\title{
Attention Shifts Recruit the Monkey Default Mode Network
}

\author{
John T. Arsenault, ${ }^{1,5 *}$ - Natalie Caspari, ${ }^{1,3 *}{ }^{-R i k}$ Vandenberghe, ${ }^{2,3}$ and $\odot W i m$ Vanduffel ${ }^{1,4,5}$ \\ ${ }^{1}$ Laboratory for Neuro- and Psychophysiology, Neurosciences Department, KU Leuven Medical School, 3000 Leuven, Belgium, ${ }^{2}$ University Hospitals \\ Leuven, Neurology Department, 3000 Leuven, Belgium, ${ }^{3}$ Laboratory for Cognitive Neurology, Neurosciences Department, KU Leuven, 3000 Leuven, \\ Belgium, ${ }^{4}$ Harvard Medical School, Boston, Massachusetts 02115, and ${ }^{5}$ Massachusetts General Hospital, Martinos Center for Biomedical Imaging, \\ Charlestown, Massachusetts 02129
}

A unifying function associated with the default mode network (DMN), which is more active during rest than under active task conditions, has been difficult to define. The DMN is activated during monitoring the external world for unexpected events, as a sentinel, and when humans are engaged in high-level internally focused tasks. The existence of DMN correlates in other species, such as mice, challenge the idea that internally focused, high-level cognitive operations, such as introspection, autobiographical memory retrieval, planning the future, and predicting someone else's thoughts, are evolutionarily preserved defining properties of the DMN. A recent human study demonstrated that demanding cognitive shifts could recruit the DMN, yet it is unknown whether this holds for nonhuman species. Therefore, we tested whether large changes in cognitive context would recruit DMN regions in female and male nonhuman primates. Such changes were measured as displacements of spatial attentional weights based on internal rules of relevance (spatial shifts) compared with maintaining attentional weights at the same location (stay events). Using fMRI in macaques, we detected that a cortical network, activated during shifts, largely overlapped with the DMN. Moreover, fMRI time courses sampled from independently defined DMN foci showed significant shift selectivity during the demanding attention task. Finally, functional clustering based on independent resting state data revealed that DMN and shift regions clustered conjointly, whereas regions activated during the stay events clustered apart. We therefore propose that cognitive shifting in primates generally recruits DMN regions. This might explain a breakdown of the DMN in many neurological diseases characterized by declined cognitive flexibility.

Key words: attention; cognition; DMN; fMRI; monkey

Significance Statement

Activation of the human default mode network (DMN) can be measured with fMRI when subjects shift thoughts between highlevel internally directed cognitive states, when thinking about the self, the perspective of others, when imagining future and past events, and during mind wandering. Furthermore, the DMN is activated as a sentinel, monitoring the environment for unexpected events. Arguably, these cognitive processes have in common fast and substantial changes in cognitive context. As DMN activity has also been reported in nonhuman species, we tested whether shifts in spatial attention activated the monkey DMN. Core monkey DMN and shift-selective regions shared several functional properties, indicating that cognitive shifting, in general, might constitute one of the evolutionarily preserved functions of the DMN.

\section{Introduction}

The human default mode network (DMN) consistently decreases its activity during task performance, compared with rest (Shul-

\footnotetext{
Received April 25, 2017; revised Nov. 6, 2017; accepted Dec. 8, 2017.

Author contributions: R.V. and W.V. designed research; N.C. and W.V. performed research; J.T.A., N.C., and W.V. contributed unpublished reagents/analytic tools; J.T.A. and N.C. analyzed data; J.T.A., N.C., R.V., and W.V. wrote the paper.

This work was supported by Inter-University Attraction Pole 7/11 to W.V. and R.V.; Research Foundation Flanders Senior Clinical Investigator Grant, G0660.09 and G0A09.13 to R.V., and G0A5613, G.062208.10, G0B8617N, and Odysseus G0007.12 to W.V.; KU Leuven 0T/12/097 to R.V.; Programme Financing PFV/10/008 to R.V. and W.V.; European Union Seventh Framework Grant Agreement 604102 (Human Brain Project, SGA1) to W.V.; and Hercules to W.V and R.V., J.T.A. is a postdoctoral fellow of FWO. We thank S. Verstraeten, M. De Paep, W. Depuydt, A. Coeman, C. Fransen, P. Kayenbergh, I. Puttemans, C. Ulens, S. De Pril, A. Hermans, and G. Meulemans for technical and administrative support; and S. Raiguel for comments on the manuscript.

The authors declare no competing financial interests.
}

man et al., 1997; Raichle et al., 2001). Furthermore, the DMN is activated during a number of high-level internally directed cognitive processes, such as autobiographical memory retrieval, planning the future, imagining the perspectives of others, or even daydreaming (Buckner and Carroll, 2007; Mason et al., 2007; Buckner et al., 2008; Spreng et al., 2008; Andrews-Hanna et al., 2010). Reduced DMN activity has also been correlated with improved task performance and memory encoding (Otten and Rugg, 2001; Daselaar et al., 2004; Li et al., 2007). On the other hand, the DMN has

\section{*J.T.A. and N.C. contributed equally to this study.}

Correspondence should be addressed to Dr. Wim Vanduffel, Laboratory for Neuro- and Psychophysiology, KU Leuven Medical School, 3000 Leuven, Belgium. E-mail:wim@nmr.mgh.harvard.edu.

DOI:10.1523/JNEUROSCI.1111-17.2017

Copyright $@ 2018$ the authors $\quad 0270-6474 / 18 / 381202-16 \$ 15.00 / 0$ 
been implicated in monitoring the external world for unexpected events, exhibiting a broad low-level focus of attention (Buckner et al., 2008). This is in line with studies where the recruitment of DMN regions correlated with faster reaction times following unexpected target events (Gilbert et al., 2006; Hahn et al., 2007; Sadaghiani et al., 2009). However, DMN correlates were reported also in other species, including mice (Rilling et al., 2007; Vincent et al., 2007; Mantini et al., 2011; Lu et al., 2012; Stafford et al., 2014), challenging the idea that the above listed internally focused, high-level cognitive operations are the main evolutionarily preserved defining property of the nonhuman DMN. Key characteristics of neurological and psychiatric diseases, such as Alzheimer's disease, schizophrenia, depression, and autism, may be instrumental in helping resolve this conundrum. First, core nodes of the DMN are affected at disease onset (Leech and Sharp, 2014; Utevsky et al., 2014). Second, a common symptom of patients suffering from these diverse pathologies is the breakdown of cognitive-shifting abilities, a property that is critically important in everyday life (Perry and Hodges, 1999; Berger et al., 2003; Reichenberg and Harvey, 2007; Waltz et al., 2013). Moreover, it has recently been shown that high-level executive control requiring major revisions of cognitive context significantly activated human DMN regions (Crittenden et al., 2015). To test the generality of the latter finding, we hypothesized that mental-shifting operations between series of internal thoughts or memories (e.g., during autobiographical memory, mind wandering, imaging the future, or theory-of-mind like operations), but also shifts during the passive and seemingly indifferent observation of the environment, might constitute one of the evolutionarily preserved functioning principles of the DMN. If true, the DMN should be more active during conditions requiring more shifting operations compared with conditions with fewer shifts, and critically important, also in nonhuman species. Therefore, we aimed to study monkey DMN functions by experimentally controlling cognitive shifts using a selective covert spatial attention task. Large ruledriven changes in attentional context (shift events) consisted of the reallocation of attentional weights in space and were compared with small changes when attentional weights were maintained at the same location (stay events). This comparison was done in analogy to a recent human study during which sufficiently large as opposed to small changes in cognitive context recruited DMN regions (Crittenden et al., 2015). First, we aimed to investigate to which degree shift and stay selective activations in monkeys differed in their spatial overlap with the DMN. Therefore, the DMN was characterized using four complementary methods and compared with cortical regions engaged during attention conditions, requiring large attentional shifts compared with very similar task conditions requiring comparably small shifts. Specifically, we scanned 3 monkeys (Vanduffel et al., 2001) with a challenging covert spatial attention task (Caspari et al., 2015) previously used in humans to identify attentional shifting areas in the superior parietal lobule (Molenberghs et al., 2007). We predicted that attentional 1 shifting, as opposed to sustained contralateral attention during the same task, would activate areas coinciding with the DMN.

\section{Materials and Methods}

Animal care and experimental procedures were performed in accordance with the National Institute of Health's Guide for the care and use of laboratory animals, European legislation (Directive 2010/63/EU) and were approved by the Ethical Committee of KU Leuven. The details of the general fMRI procedures and training of monkeys have been described previously (Vanduffel et al., 2001; Nelissen et al., 2005). The attention data have been described in detail previously (Caspari et al., 2015).

\section{Subjects and training}

Three rhesus monkeys, including 2 females (M13, M24, and M35; Macaca mulatta; 3-6 kg; 3-9 years of age) participated in the experiments. Whereas M24 and M35 participated only in the present experiment, M13 was a subject in previous fMRI experiments (fixation, free viewing, auditory, and saccade tasks). Animal housing and handling were in accordance with the recommendations of the Weatherall report, allowing locomotor behavior, social interactions, and foraging. All animals were group-housed (cage size at least $16-32 \mathrm{~m}^{3}$ ) with cage enrichment (toys, foraging devices) at the primate facility of the KU Leuven Medical School. They were fed daily with standard primate chow supplemented with bread, nuts, raisins, prunes, and fruits. The monkeys were exposed to natural light conditions, with additionally $12 \mathrm{~h}$ of artificial light throughout the year, independent of the season. The animals received their daily water supply during the experiments until satiated.

Monkeys were trained daily, during the normal light-on period for several hours, in a mockup of an MRI scanner for all tasks. They were scanned following several months $(\sim 4)$ of training, when fixation performance exceeded $90 \%-95 \%$, and when false-alarm rates were close to $0 \%$. The monkey sat in a sphinx position, head fixed to the plastic monkey chair, directly facing the screen. Eye positions were monitored at $120 \mathrm{~Hz}$, using pupil position and corneal reflection (Iscan).

\section{Monkey fMRI}

Contrast-agent-enhanced functional images (Vanduffel et al., 2001; Leite et al., 2002) were acquired with a 3.0 tesla horizontal bore full-body scanner (TIM Trio; Siemens Healthcare). The same data were used as in Caspari et al. (2015) and Caspari et al. (2017) for describing the attentional shift network in monkeys, however completely outside the context of the DMN. All other data are novel. Using a gradient-echo $\mathrm{T} 2{ }^{\star}$-weighted EPI sequence, we acquired data for the ( 1 ) selective attention task [ 40 horizontal slices; TR, $2 \mathrm{~s}$; TE, $17 \mathrm{~ms}$ (M13, M24), $19 \mathrm{~ms}$ (M35); $1.25 \times 1.25 \times 1.25 \mathrm{~mm}^{3}$ isotropic voxels, image acceleration factor of 3 (M13, M24), or 2 (M35)] and (2) the resting state scans used for the functional connectivity analyses [36 horizontal slices; TR of $1.4 \mathrm{~s}$; TE, $16 \mathrm{~ms} ; 1.25 \times 1.25 \times 1.25 \mathrm{~mm}^{3}$ isotropic voxels, image acceleration factor of 3 (M13, M24), or 2 (M35)]. M13 was scanned with a custom-built, eight-channel phased-array receiver coil, and a saddle-shaped, radial transmit-only surface coil (Kolster et al., 2009). M24 and M35 had been implanted with 8- and 5 -channel receiver coil arrays, respectively, mounted on top of the skull, beneath the headpost, improving sensitivity for MRI (Janssens et al., 2012). Temporal signal-to-noise (tSNR) calculations of the dorsal half of the brain covering the regions of interest (ROIs) clearly showed the benefit of implanted higher-channel coils: M13 (8 channel external): tSNR = 46.24, M24 (8 channel implant): tSNR $=140.14$. M35 (5 channel implant): $\mathrm{tSNR}=63.50$. Scanning of M24 was performed with the same scanner, main parameters, and transmit coil as with M13, but with the addition of a $36 \mathrm{~cm}$ inner-diameter head gradient set (AC88, maximum strength: $80 \mathrm{mT} / \mathrm{m}$; maximum slew rate: $800 \mathrm{~T} / \mathrm{m} / \mathrm{s}$ ). The resting state scans of M35 were also performed with the AC88 (to reach the same parameters as for M13/M24 with the 5-channel implant coils). Slices were oriented transversally, covering the entire brain. As MION (Sinerem; Laboratoire Guerbet,or Feraheme) measurements depended only on blood volume (Mandeville and Marota, 1999), all signal values have been inverted.

The main selective-attention task was scanned using an event-related design, and a run lasted $610 \mathrm{~s}$ (305 volumes, including 4 dummy volumes). The localizer experiment to assess the stimulus representation was scanned with a block design with the same parameters as the selective attention experiment, a run lasting $490 \mathrm{~s}$ ( 245 volumes, including 4 dummy volumes), as described above. The resting-state scans were acquired at a different date after the selective attention and localizer experiments, subjects awake while fixating, with runs lasting $590.8 \mathrm{~s} \mathrm{(422}$ volumes, including 4 dummy volumes).

High-resolution anatomical images were acquired for each monkey in separate scan sessions under anesthesia, using a single radial transmit- 
receive surface coil and an MPRAGE sequence (TR, 2200 ms; TE, 4.05 ms; 208 slices; 0.4 mm isotropic voxel size).

\section{Stimuli and tasks}

For the selective-attention task, the experimental setup was adapted from the human experiment performed by Molenberghs et al. (2007), exactly as used by Caspari et al. (2015). Two stimuli occupied opposite locations to the left and right of center and on the horizontal meridian at 9.25 degrees eccentricity (Fig. 1I). There were two possible linked stimulus pairs: a square with a triangle or a circle with a diamond. All stimuli were white on a black background and matched in area $\left(1.59 \mathrm{deg}^{2}\right)$. Each stimulus pair contained a relevant and an irrelevant stimulus. Monkeys were extensively trained to distinguish relevant from irrelevant shapes. When the relevant, but not the irrelevant, shape dimmed (e.g., the square or the circle), the monkey had to respond by manually interrupting a light beam to receive a liquid reward. Monkeys thus covertly displaced or maintained their attentional focus together with the relevant stimuli in a rule-based manner. The allocation of attention was probed by the randomly inserted dimming events. The dimmings ( $100 \mathrm{~ms}$ ) were rare ( $14 \%$ of relevant and of irrelevant stimuli) with the luminance contrast (gray level) set at detection threshold. M13 and M24 responded during 50\% of all scan sessions with the right hand and to the other half with the left, M35 with the left hand only.

The sustained attention baseline was transiently interrupted by one of two event types consisting of a replacement (without temporal gaps) of one stimulus pair by another after $2250 \mathrm{~ms}$, occupying the same two positions. In the first event type (Fig. 1I,III), the relevant stimulus of the new pair appeared at the position previously occupied by the irrelevant stimulus of the preceding pair, and vice versa. This feature change, in altering the position of the relevant stimulus, elicited a shift in spatial attention (shift event). A "shift-right" event (Fig. 1I) corresponded to a spatial shift of the relevant stimulus from the left to the right hemifield, and a "shift-left" (Fig. 1III) to a spatial shift from right to left.

In event Type 2 (Fig. 1II,IV), the relevant stimulus of the new pair appeared at the same position as the relevant stimulus of the preceding pair. Hence, the relevant stimulus site remained unchanged, inducing no spatial shift in attention. This was called a stay event: "stay-right" (Fig. $1 I I$ ) or "stay-left" (Fig. 1IV). With this event, attention was already deployed to the target location before the feature change (event onset). One-third of all trials were null events (Fig. $1 \mathrm{~V}$, "null left"). During these events, the stimuli remained on the screen without being changed. Each run contained an equal number of shift, stay, and null events. The positions occupied by the stimuli, as well as the number of relevant and irrelevant dimming events, were matched across event types. Dimmings were equally distributed between 50 and $1500 \mathrm{~ms}$ after event onset and temporally dissociated from the actual events of interest: the stay, shift, and null events. Importantly, relevant and irrelevant dimming trials used to probe the allocation of attention were rare ( $14 \%$ of the trials). During task performance, eye movements, reaction times, hits, misses, and false alarms were measured and have been reported by Caspari et al. (2015).

During the localizer and resting state, scans monkeys were awake and rewarded for fixation on a red square $(0.3 \times 0.35$ visual degrees $)$ in the center of the screen.
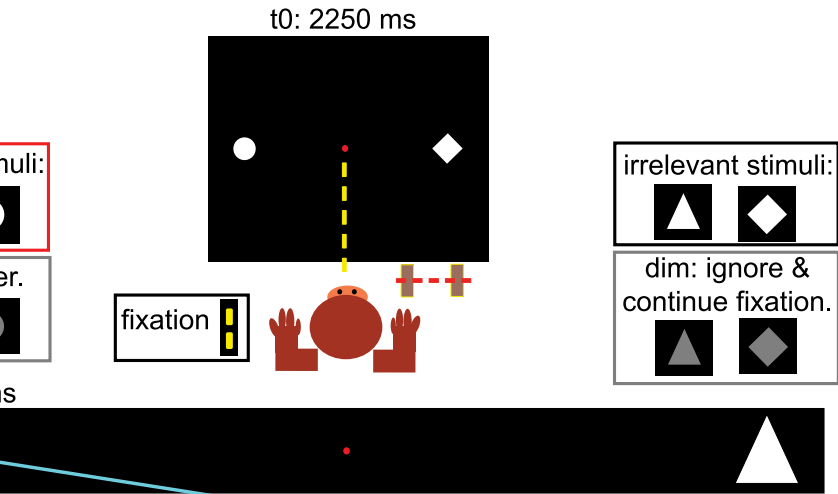

ms I shift (to right)

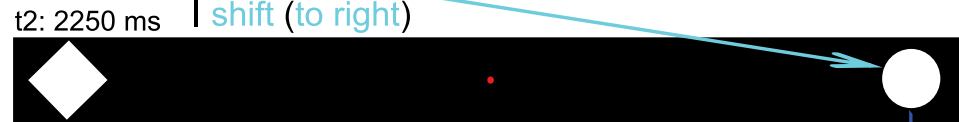

II stay (right)

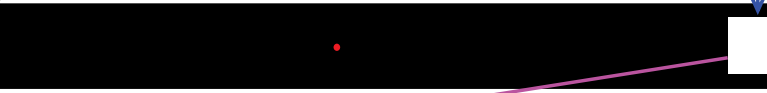

III shift (to left)

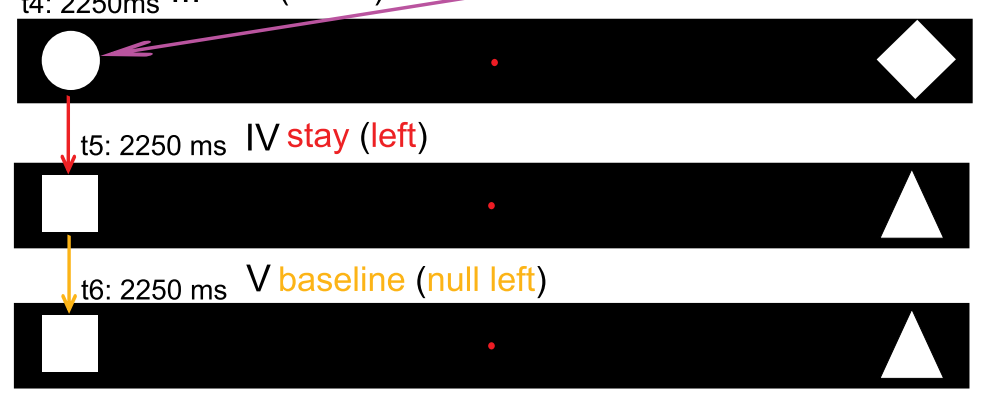

tn: $2250 \mathrm{~ms}$

Figure 1. Stimuli and task used to measure covert spatial attention shifts. Top, Schematic of display viewed by the monkey. One f the two stimulus pairs (each consisting of a relevant and an irrelevant shape) was presented at any given time while the monkey by the succeeding pair after $2250 \mathrm{~ms}$, resulting in a shift $(\boldsymbol{I}, \boldsymbol{I I I})$, stay $(\boldsymbol{I I}, \boldsymbol{I V})$, or null $(\boldsymbol{V}$, null left) event. The monkey's attention was locked to the relevant stimulus (square or circle) and shifted (or stayed) with it during consecutive stimulus displays.

\section{fMRI data analysis}

Preprocessing. The raw EPI images were corrected for the lowest-order off-resonance effects and aligned with respect to the GRE reference images before performing a SENSE image reconstruction (Pruessmann et al., 1999). Residual N/2 artifacts in the reconstructed images were removed using an algorithm based on the UNFOLD method (Madore et al., 1999) and were further corrected for higher-order distortions using a nonrigid slice-by-slice distortion correction (Kolster et al., 2009). Subsequent data analysis was performed with the SPM5 software package (http://www.fil.ion.ucl.ac.uk/spm), running under MATLAB (The MathWorks). The functional image time series were preprocessed to compensate for slice-dependent time shifts, motion corrected within and across sessions, and linearly detrended, then coregistered to the anatomical image, and finally spatially normalized to the 112RM template (McLaren et al., 2009) aligned to the F99 surface-based atlas (Van Essen et al., 2001), with a voxel size of $1 \times 1 \times 1 \mathrm{~mm}$. Images were smoothed with a $1.5 \mathrm{~mm}$ kernel.

Data analysis of main experiment (event-related). The following events entered the GLM: stay events, composed of a feature change (Fig. 1II, stay-right, $I V$, stay-left); shift events, composed of a feature change and a spatial shift (Fig. $1 I$, shift-right, $I I I$, shift-left); and null events (Fig. $1 V$, null left, no feature change). An equal number of null-left and null-right events constituted the attention baseline. The number of correctly executed trials analyzed for each event type was equalized for left- and right- 
sided attention. Only trial sequences with at least 3 or more consecutive and correctly executed fixation trials were included in the analysis. The dimming and reward events within these series of correctly executed fixation trials were excluded from the analyses. The GLM included 5 regressors for the five conditions, 2 eye movement regressors, and 6 additional head motion regressors (translation and rotation in 3D), per run. Each condition was modeled by convolving a Gamma function (delta $=0$, tau $=8$, and exponent $=0.3$ ), modeling the MION hemodynamic response function, at the onset of the condition (transition of stimulus displays). The first two main contrasts of interest were stay-left versus stay-right (contrast 1 ) and vice versa (contrast 2). These delineated areas reflecting the current locus of attention and will be deemed "contralateral stay," relative to the observed hemisphere.

Activations correlating with "transient" spatial attention shifts regardless of the direction of the shift were visualized by contrasting bilateral "shifts" versus "stay" (shift-left and shift-right vs stay-left and stay-right, contrast 3).

Data were first analyzed per subject and scanning day (session) with a fixed-effects GLM. Runs with fixation performances $<85 \%$ were excluded. For M13, this resulted in 9 sessions with a total of 131 runs (an average of 15 runs/session), for M24, 12 sessions with a total of 181 runs (an average of 15 runs/ session), and for M35, 10 sessions with a total of 171 runs (averaging 17 runs/ session) that were included in the analyses. Next, we computed a session-wise second-level mixed-effect analysis (MFX) (Friston et al., 2005), with the "con-images" of contrasts 1-3, obtained from the first level analyses as input, including a total of 31 images per contrast [9 (M13) +12 (M24) +10 (M35) sessions]. All statistical maps were based on this MFX analysis and were shown at a threshold of $p=0.01$, both uncorrected. The relatively low threshold for the shifting contrast was justified since we had a clear a priori hypothesis concerning superior parietal involvement (Caspari et al., 2015). Second, to compute raw time courses for the group, we performed a group fixedeffects analysis (FFX). This was done by selecting the best 69 runs of each animal based on behavioral performance (percent fixation and responseperformance), analyzed in group space. These 207 runs were pooled for the FFX analysis, and the final contrasts (same as used in the MFX analysis) were thresholded at familywise error (FWE, $p<0.05$ ). This procedure was performed to extract time courses and beta values for only those clusters reaching the above-mentioned threshold in the statistically more stringent MFX analysis. Importantly, all reported ROIs of the MFX analysis were also present in the corresponding contrasts at FWE correction of the group FFX.

Finally, FFX analyses were performed in each single subject for the event-related task, and the corresponding contrasts (1-3) were thresholded at $p<0.0001$ for M24 and M35, and at $p<0.001$ in M13; because of lower SNR, as it was scanned without implant coils (Janssens et al., 2012).

A cluster extent threshold of 10 voxels was applied to all volume maps. Analysis of stimulus localizer data (block design) to define "DMN fixation versus visual." The data from the stimulus localizer experiment were preprocessed and analyzed the same way as the event-related data of the main experiment, using a GLM. Data were first subjected to sessionwise FFX analyses for each animal: 2 scanning days per monkey, M13: 26 runs, M24: 35 runs, M35: 44 runs. The onset of each condition (1, red fixation dot only, "stimulus OFF" or "stimulus ON" conditions; 2, bilateral; 3, unilateral left; 4, unilateral right stimulus display) was modeled over the entire $20 \mathrm{~s}$ block extent. The FFX $t$ maps used to calculate the single monkey and group "task-related deactivations" (DMN Fixation vs Visual) were obtained by contrasting the fixation-only condition (1) with all the "stimulus ON conditions" (2-4), and thresholded at FWE ( $p=$ 0.05 ) correction in the group and the single subjects. In M13 (scanned without implant coils), blocked design localizer maps were thresholded at $p<0.0001$ uncorrected.

Analysis of the resting state data. We acquired two sessions of resting state scans per monkey and included all runs with a minimal fixation performance of 87\%: M13: 16 runs (1), 19 runs (2); M24: 19 runs (1), 17 runs (2); M35: 20 runs (1), 20 runs (2).

Independent component analysis (ICA) to define "DMNic." Spatial ICA extracts maximally independent patterns of coherent fMRI activity (Cal- houn et al., 2001), and was applied to the datasets of the group ( 2 sessions per monkey), and for each single monkey by means of the GIFT toolbox. The estimation of the number of independent components (ICs) was performed using the minimum description-length criterion (Calhoun et al., 2001). As we were interested only in determining the DMN component for the group and in each subject, we set the number of components to be estimated to 20, thus approximating model orders commonly used in human studies of large-scale brain networks (Calhoun et al., 2001; Smith et al., 2009; Abou-Elseoud et al., 2010). After reduction of dimensionality by means of principal component analysis (accounting for at least $99.99 \%$ explained variance), ICs were retrieved by means of the fast ICA algorithm, with a deflation approach and hyperbolic tangent (tanh) nonlinearity (Esposito et al., 2005; Mantini et al., 2013). Component time courses and spatial maps for each session were then back-reconstructed using the aggregate components and the results from the data reduction step (Calhoun et al., 2001). To quantify the reliability of the decomposition, ICA was reiterated 10 times using the ICASSO toolbox (Himberg et al., 2004), resulting in a stability index. Stability indices for each estimatecluster approaching 1 would indicate a close-to-orthogonal and highly consistent component, stable across multiple ICA runs. All the ICs obtained were scaled to empirically derived $z$ scores (dividing by the SD of the original time course), representing the correlation strength of each voxel and the associated component. Applying the spatial correlation sorting option in GIFT (Correa et al., 2007) with respect to the mask of the model monkey DMN as reported by Mantini et al. (2011) (defined from a task-related deactivation meta-analysis in 10 monkeys, the hallmark of the DMN), we selected the best matching DMN component in the group and each single animal, which we called "DMN task" (or "DMNt") throughout the paper. Two components (one that overlapped well with frontal cortex and one that overlapped with parietal cortex) were selected for the frontal-parietal network. A minimal $z$ score of 1 was used as the lower limit threshold for the functional connectivity (Hutchison et al., 2011).

Seeding to define "DMNseed." The resting-state data were additionally preprocessed in preparation for functional connectivity analysis, according to previously described procedures (Vincent et al., 2007; Mantini et al., 2011), and will only be described briefly. The processing steps included (1) bandpass filtering (between 0.0025 and $0.05 \mathrm{~Hz}$ ); (2) regression of white matter and ventricle signals, and their first derivatives; and (3) regression of 3D motion parameters, and their first derivatives. "DMNseed" was defined by placing $2 \mathrm{~mm}$ midline spherical seed in the posterior cingulate cortex (PCC) (areas 23/31, coordinate 0-25 10 in RM112 in F99 space aligned to the anterior commissure). This location was chosen to minimize confounds due to differential seed selection (Margulies et al., 2009; Hutchison and Everling, 2012). The average time course signal in the ROI was obtained (across voxels), and a whole brain connectivity map was created and converted to $z$ scores by the Fisher's $r$-to- $z$ transformation (Zar, 1998), correcting the degrees of freedom for the autocorrelation in the time series (Shumway and Stoffer, 2006). A FFX across all runs (of the group or of each single monkey) was used to create group-level or single-subject correlation maps (Genest, 1992), and thresholded at FWE correction $(p=0.05)$.

Correlation analysis and hierarchical clustering. Following the same statistical approach as described above (Seeding to define "DMNseed"), $Z$ score maps were then back-converted to correlation maps by the Fisher's $z$-to-r transform (Zar, 1998), and plotted. A correlation matrix between the ROI time courses was calculated with the seeds ( $2 \mathrm{~mm}$ spheres around the local maxima) of (1) DMNic, (2) DMNt, (3) all shift, and all stay (4) ROIs (3 and 4 were described by Caspari et al., 2015). Seeds were chosen according to positions of overlap of the $3 \mathrm{DMN}$ definitions as seen in Figure $4 A$ [areas PGm/31/V6A, left and right PO/V6, bilateral posterior superior temporal sulcus (STS) regions termed caudal temporal parietal occipital (TPOC), and caudal area 46, as well as the frontal eye field (FEF), where the activation was present in the volume of DMNic], excluding the overlap in the calcarine (most ventral part on the flat map; see Fig. 4A), and listed in Table 1. Significances in the average correlation matrices were calculated based on the statistics of the session-wise MFX ( 2 sessions per subject, with a total of 6 ). Thus, each session was treated as a separate subject and significance threshold was a set to $p<0.001$. 

Table 1. Local maxima and origin of ROls entering the cross-correlation matrix and
dendrogram $^{a}$

\begin{tabular}{|c|c|c|}
\hline Brain area & Network & $\begin{array}{l}\text { RM112-in F99 atlas } \\
x, y, z\end{array}$ \\
\hline LP0/V6 & DMNic & $-6,-38,8$ \\
\hline RPO/V6 & DMNic & $6,-39,8$ \\
\hline LTPOC & DMNic & $-21,-29,9$ \\
\hline RTPOC & DMNic & $22,-28,9$ \\
\hline L area 46 & DMNic & $-12,10,12$ \\
\hline Rarea 46 & DMNic & $14,9,12$ \\
\hline L area 31/V6A & DMNt & $-5^{b}-35^{b} 12^{b}$ \\
\hline Rarea 31/V6A & DMNt & $5,-34,12$ \\
\hline LPGM & DMNt & $-1,-28,17$ \\
\hline RPGM & DMNt & $1,-27,18$ \\
\hline L area 8/FEF & DMNt & $-10,7,18$ \\
\hline R area 8/FEF & DMNt & $10,8,18$ \\
\hline $\mathrm{LCmOC}$ & Shift & $-3,-41,4$ \\
\hline $\mathrm{Remoc}$ & Shift & $5,-38,4$ \\
\hline R V6 & Shift & $5,-37,7$ \\
\hline L V6A & Shift & $-5^{b}-35^{b} 12^{b}$ \\
\hline R V6A & Shift & $6,-37,13$ \\
\hline V6 medial & Shift & $0,-36,12$ \\
\hline L MIP & Shift & $-6,-32,14$ \\
\hline LTOPC & Shift & $-15,-29,14$ \\
\hline RTPOC & Shift & $13,-29,15$ \\
\hline LACC & Shift & $-4,13,13$ \\
\hline RACC & Shift & $3,14,16$ \\
\hline LaPCS & Shift & $-12,17,11$ \\
\hline L area 46 & Shift & $-17,12,13$ \\
\hline Rarea46 & Shift & $15,11,11$ \\
\hline L area 12 & Shift & $-21,9,4$ \\
\hline Rarea 11-12 & Shift & $20,11,6$ \\
\hline L somM & Shift & $-16,-9,13$ \\
\hline R area F6 & Shift & $2,5,21$ \\
\hline LV1 & Stay & $-6,-48,6$ \\
\hline R V1 & Stay & $9,-50,5$ \\
\hline L V3V & Stay & $-15,-39,-7$ \\
\hline R V3v & Stay & $16,-39,-6$ \\
\hline L V $4 v$ & Stay & $-23,-31,-8$ \\
\hline R V 4v & Stay & $25,-32,-8$ \\
\hline LLIP & Stay & $-10,-26,16$ \\
\hline R LIP & Stay & $12,-26,16$ \\
\hline LFST & Stay & $-22,-23,-3$ \\
\hline RFST & Stay & $22,-24,-2$ \\
\hline L TEA & Stay & $-22,-4,-12$ \\
\hline R TEA & Stay & $21,-4,-12$ \\
\hline L vcau & Stay & $-14,-6,-10$ \\
\hline R vcau & Stay & $16,-7,-9$ \\
\hline L dcau & Stay & $-5,-6,8$ \\
\hline Rdcau & Stay & $5,-2,8$ \\
\hline L area 45 & Stay & $-18,9,8$ \\
\hline Rarea 45 & Stay & $18,9,9$ \\
\hline
\end{tabular}

${ }^{a}$ Column 1, ROI position abbreviations (see Definition of anatomical labels). Same conventions as in Figure 2: L, Left hemisphere; $\mathrm{R}$, right hemisphere; $v$, ventral; $d$, dorsal; cau, caudate nucleus; somM, somatomotor; MIP, medial intraparietal area; TEA, anterior temporal area; FST, fundus of the STS area; LIP, lateral intraparietal area; ACC, anterior cingulate area; aPCS, anterior principal sulcus. Column 2, Definition of network/contrast based on which the ROl has been defined. Same conventions as in Figures 2-7: DMNic, defined with means of group ICA (GIFT-toolbox) using independent resting-state data across the 3 animals. The spatially best-correlating component with the DMN of Mantini et al. (2011) (DMNt) was defined as DMNic component (using spatial template matching by the GIFT toolbox). DMNtask (DMNt) (Mantini et al., 2011), defined in a meta-analysis of task related deactivations across 15 experiments. "Shift" and "stay" networks obtained from the MFX of a selective attention experiment (Caspari et al., 2015) (for more details, see Experimental procedures), distinguishing areas activated for attention shifts (shift) as opposed to areas activated by contralateral allocation of attention (stay). "Shift" ROls are obtained from contrast shift (left/right) versus stay (left/right). "Stay"' ROls in the left hemisphere are defined with contrast 2 (stay right vs stay left), and in the right hemisphere with contrast 1 (stay right vs stay left). Column $3, x, y, z$ coordinates in RM-112-inF99 space, centered on the anterior commissure.

${ }^{b}$ Same local maximum in DMNt and shift networks.

Next, to visualize the unsupervised clustering of all the ROIs of the three different networks (default mode, shift, and stay) based on their functional correlation values, we applied hierarchical cluster analysis using the average linkage algorithm (Everitt et al., 2001; Mantini et al., 2011).
Surface-based projections. For visualization on flat maps or inflated brains, the resulting $t$ maps from the MFX analyses were projected onto the macaque F99 brain (Van Essen, 2004). Flat maps were created using FreeSurfer (http://surfer.nmr.mgh.harvard.edu/). All surface maps where thresholded at a minimal surface area extent of $30 \mathrm{~mm}^{2}$ (http://surfer.nmr.mgh.harvard.edu/fswiki/mri_surfcluster).

Definition of anatomical labels. The anatomical labels used to designate the positions of our activations on inflated F99-brain surfaces were derived from three independent sources. Area labels for V1, V2, V3, V4, V4A, PITd, PITv, and area MT were derived from previous retinotopy experiments, combining data from 5 monkeys (probability maps of $50 \%$ overlap, including M13 and M24) (Janssens et al., 2014). Lateral intraparietal (LIP) (pooled LIPa and LIPi), FEF, areas 11, 12, 45, 46, and V6A were based upon Nelissen et al. (2011) and on the template anatomy of M12 (Ekstrom et al., 2009), and were warped to the F99 surface using the FreeSurfer surface-to-surface registration algorithm. Activations not falling into any of those atlases were defined anatomically with the aid of the monkey atlas of Paxinos et al. (2008).

ROI and raw time course analysis. The MFX did not allow us to extract raw time courses. Raw time courses were therefore computed using data from an FFX (Friston et al., 1995; Caspari et al., 2015) using the best 69 runs, as determined behaviorally ( $\%$ fixation, $\%$ misses), from each of the 3 animals, resulting in a total of 207 runs normalized to the template. Only ROIs/activations that were present in the contrasts of the FFX analysis at FWE ( $p=0.05$, correcting for multiple comparisons) and at the same time in the more stringent corresponding MFX contrasts (as defined above) were reported (Caspari et al., 2015). Functional ROIs were defined as $2 \mathrm{~mm}$ spheres around the local maxima derived from FFX (within a mean vector distance of $1.6 \pm 0.7 \mathrm{~mm}, \pm \mathrm{SD}$, from the MFX local maximum). Percent signal change was calculated for these ROIs with the fMRI signal extracted and averaged across all voxels of the $2 \mathrm{~mm}$ sphere. The raw signal was then high-pass filtered (256 s), and an independent baseline was determined for each data point (TR) by calculating the moving average of the raw fMRI signal in a sliding window of \pm 50 data points ( \pm 100 s) (Cui et al., 2009; Arsenault et al., 2013; Caspari et al., 2015). Trials per condition were then aligned at time point zero and peristimulus time histograms were computed for each MRI run. Time courses were plotted in two ways: (1) against the sustained attention baseline (represented by the null events); and (2) against the running average baseline. Also, we computed the average time course of all ROIs listed in Table 1, averaging per time point and condition across either all ROIs of the default mode (DMNt, DMNic), all ROIs of the shift, or all ROIs of the stay left or the stay right networks (within the respective hemisphere activated for contralateral attention). The correlation coefficient was calculated comparing the average time courses per time point and condition across DMN and shift ROIs, DMN and both stay left and right ROIs. The $p$ value was computed with a $t$ statistic. To characterize the activity of the raw average DMN ROI-time course, we calculated a twoway repeated-measures ANOVA on the PSC with factors (1) shift versus stay, and (2) left versus right (Caspari et al., 2015) using STATISTICA version 12 (StatSoft 2014; www.statsoft.com).

Definition of overlap: shift voxels and DMN voxels. The DMN activation map (blue), consisting of a meta-analysis of 15 experiments $(N=$ 15) (including 10 subjects, 9 male, 1 female which corresponded to M13), compares the fixation condition versus active task (visual, attention, action-observation, auditory) (Mantini et al., 2011). This consensus map was thresholded at $N=8$, saved as a mask, rigidly aligned with the F99 brain used for segmentation in Freesurfer, and then projected onto the gray matter surface (flat map and inflated views) together with the MFX $t$ map contrasts "shift versus stay" (hot color) and "contralateral stay" (green transparent color). Surface ROIs were defined in FreeSurfer (http://surfer.nmr.mgh.harvard.edu/), and the percent overlap of shift/ stay voxels with the DMN (including gray matter voxels only) was calculated relative to the total number of shift/stay voxels, respectively. To generalize our results to other existing DMN definitions in monkey, this calculation was also performed with respect to DMNic, DMNseed, and DMN Fixation versus Visual. We also tested whether the measured overlap between the shift/stay networks and the DMN differed from an overlap based on a random distribution of shift/stay selective voxels. 
Table 2. Monkey behavior: reaction times (RTs), hits, and misses ${ }^{a}$

\begin{tabular}{|c|c|c|c|c|c|c|c|c|c|c|}
\hline & & & & & & & & & Repeated-meas & NOVA $3 \times 2$ \\
\hline & Monkey & & Null left & Null right & Stay left & Stay right & Shift left & Shift right & Condition & Side of attention \\
\hline RTs (ms) & M13 & Mean & 362.11 & 339.63 & 376.65 & 352.13 & 352.64 & 327.83 & $F_{(2,14)}=2.48$ & $F_{(1,7)}=6.35$ \\
\hline & & SD & 34.94 & 21.46 & 40.09 & 38.54 & 32.03 & 22.00 & $p=0.11$ & $p=0.04$ \\
\hline & M24 & Mean & 399.92 & 405.13 & 404.46 & 398.59 & 410.62 & 393.91 & $F_{(2,22)}=0.051$ & $F_{(1,11)}=2.12$ \\
\hline & & SD & 23.26 & 37.24 & 23.35 & 32.10 & 33.79 & 33.79 & $p=0.95$ & $p=0.17$ \\
\hline & M35 & Mean & 498.27 & 503.75 & 490.18 & 495.19 & 488.61 & 496.05 & $F_{(2,18)}=3.41$ & $F_{(1,9)}=4.89$ \\
\hline & & SD & 18.70 & 17.64 & 18.69 & 22.81 & 22.12 & 26.47 & $p=0.06$ & $p=0.05$ \\
\hline$\%$ hits & M13 & Mean & 45.85 & 67.59 & 56.81 & 67.34 & 49.41 & 68.45 & $F_{(2,14)}=1.48$ & $F_{(1,7)}=23.92$ \\
\hline & & SD & 6.75 & 5.97 & 17.17 & 7.81 & 8.51 & 11.85 & $p=0.26$ & $p=0.002$ \\
\hline & M24 & Mean & 83.05 & 87.97 & 83.53 & 83.98 & 86.33 & 86.39 & $F_{(2,22)}=1.93$ & $F_{(1,11)}=1.06$ \\
\hline & & SD & 5.05 & 4.85 & 4.11 & 5.74 & 7.11 & 4.93 & $p=0.17$ & $p=0.33$ \\
\hline & M35 & Mean & 84.57 & 80.64 & 87.28 & 81.29 & 86.74 & 85.00 & $F_{(2,18)}=1.71$ & $F_{(1,9)}=8.28$ \\
\hline & & SD & 6.36 & 5.12 & 4.41 & 6.10 & 3.15 & 5.51 & $p=0.21$ & $p=0.02$ \\
\hline$\%$ miss & M13 & Mean & 5.08 & 3.00 & 2.67 & 1.36 & 3.06 & 2.44 & $F_{(2,14)}=1.21$ & $F_{(1,7)}=1.5$ \\
\hline & & SD & 4.69 & 3.34 & 4.47 & 1.91 & 4.69 & 3.81 & $p=0.33$ & $p=0.25$ \\
\hline & M24 & Mean & 11.21 & 8.26 & 10.45 & 11.17 & 8.53 & 10.99 & $F_{(2,22)}=0.47$ & $F_{(1,11)}=0.01$ \\
\hline & & SD & 3.01 & 3.26 & 4.37 & 4.67 & 4.83 & 5.94 & $p=0.63$ & $p=0.94$ \\
\hline & M35 & Mean & 11.42 & 13.79 & 9.67 & 12.26 & 11.00 & 11.83 & $F_{(2,18)}=0.66$ & $F_{(1,9)}=3.19$ \\
\hline & & SD & 4.74 & 5.67 & 3.57 & 3.26 & 3.33 & 4.71 & $p=0.53$ & $p=0.11$ \\
\hline
\end{tabular}

${ }^{a}$ Behavioral parameters from sequences of at least 3 consecutive correct trials plus the trial leading to an abort of the sequence. Data (mean and SD) are displayed per condition and per monkey. Daywise (M13: $8 \mathrm{~d}$; M2: $12 \mathrm{~d}$; M35: $10 \mathrm{~d}$ ) repeated-measures ANOVAs with factors condition (3: stay, shift, null) $\times$ direction of attention (2: left, right). Dimming of relevant stimulus (response trial): RTs means and SD as shown in Figure 2A. Percent hits (\% hit) of total relevant dimmings per condition. Percent missed dimmings (\% misses) of total relevant dimmings.

Therefore, we randomly shuffled $(1000 \times)$ the location of the shift and stay voxels along the cortical sheet, and calculated each time the overlap with the four DMN definitions. We normalized the values by the total number of shift or stay selective voxels to calculate the fraction of shift and stay voxels that overlap by chance within the DMN. $p$ values were calculated by determining how often the observed (nonshuffled) percent overlap would be obtained by chance.

\section{Results}

Importantly, attention-related changes during shift and stay events were temporally dissociated from the rarely occurring dimming events used to measure behavioral compliance. Eye movements, reaction times, hits, misses and false alarms have previously been reported (Caspari et al., 2015) and are summarized in Table 2.

\section{Topological comparison of DMN, shift, and stay networks}

We specifically wanted to compare fMRI activity during periods requiring many versus few cognitive shifts, which can be captured by contrasting activations induced by shift and stay events during a covert spatial attention tasks. Specifically, shift-sensitive activations were defined by contrasting bilateral shift (shift left and shift right) with stay events (stay left and stay right) (Fig. 2, hot colors). Both events were visually matched and differed only with respect to the spatial reallocation of attentional weights during the cognitive shift event. More widespread shift-selective activations (shift vs stay) were observed in posterior parietal cortex, caudomedial occipital cortex (cmoc) and the most caudal tip of the STS: that is, the caudal temporal parietal occipital area TPOC. Additionally, small frontal foci, including subcompartments of areas $46, \mathrm{~F} 6,11,12$, and anterior cingulate cortex, were bilaterally activated. Overall, the shift activations were spatially segregated from stay-selective activations (defined by the contrasts stay left vs stay right and vice versa), predominantly located in lateral occipital and ventral temporal cortex (Fig. 2, green).

Next, we compared shift-selective activations with the monkey DMN, using a meta-analysis of task-specific deactivations across 15 monkey experiments (Mantini et al., 2011) (Fig. 2, blue). Specifically, in 10 animals, we contrasted rest with active task conditions, the original definition of the DMN (Raichle et al., 2001; Hutchison and Everling, 2012). A high overlap between shift- selective and DMN voxels was observed (left hemisphere [LH], $51 \%$; right hemisphere $[\mathrm{RH}], 57.8 \%$; Fig. 2, hot color and blue overlay), in contrast to a very small overlap between voxels activated for sustained contralateral attention and DMN voxels $(\mathrm{LH}$, 5.2\%; RH, 8.3\%; Fig. 2, green and blue overlay). The strongest overlap was located in caudomedial and parietal cortex and the posterior tip of the STS (TPOC). Specifically, in frontal cortex, the overlap between shift and DMN voxels was less complete, or partially merged with stay selective voxels. In bilateral area 46, stay, shift, and DMN regions abutted, whereas they largely overlapped in ACC, and on the lateral and medial banks of the intraparietal sulcus.

\section{Raw fMRI time courses of DMN, shift, and stay networks}

The hallmark of the DMN is its higher activity level during rest compared with active tasks, as also shown by single-cell recordings in monkey (Hayden et al., 2009). How then can the current results be reconciled with shift-selective activations in posterior parietal cortex showing increased activity levels relative to baseline (null events)? These apparent discrepancies may be explained by the type of baseline used to determine "activations". Instead of using the more traditional manner of plotting activity data against a baseline condition (null events in the present experiment, which indeed also require significant attentional deployment; Fig. $3 B, D$ ), the raw time courses were evaluated against a baseline moving average (sliding window of \pm 50 data points, i.e., \pm 100 s, see ROI and raw time course analysis) with respect to the target event (Cui et al., 2009; Arsenault et al., 2013; Caspari et al., 2015) (Fig. 3C,E, for shift and stay ROIs, respectively). This approach has the advantage that it displays the raw time course of all conditions without any preassumptions about a baseline condition, hence the "real" fMRI signal after general detrending. Plotting all conditions against the baseline moving average revealed a clear pattern of deactivation for all conditions in all shift-selective foci as seen for the examples in Figure $3 C$ (posterior parietal cortex and area 46), and the average time course of all shift ROIs (Fig. $3 G$ ). Critically, this pattern did not emerge in any of the areas selectively activated for sustained contralateral attention, as shown for example areas TEAm and 45 in Figure 3D, E, and for all areas 


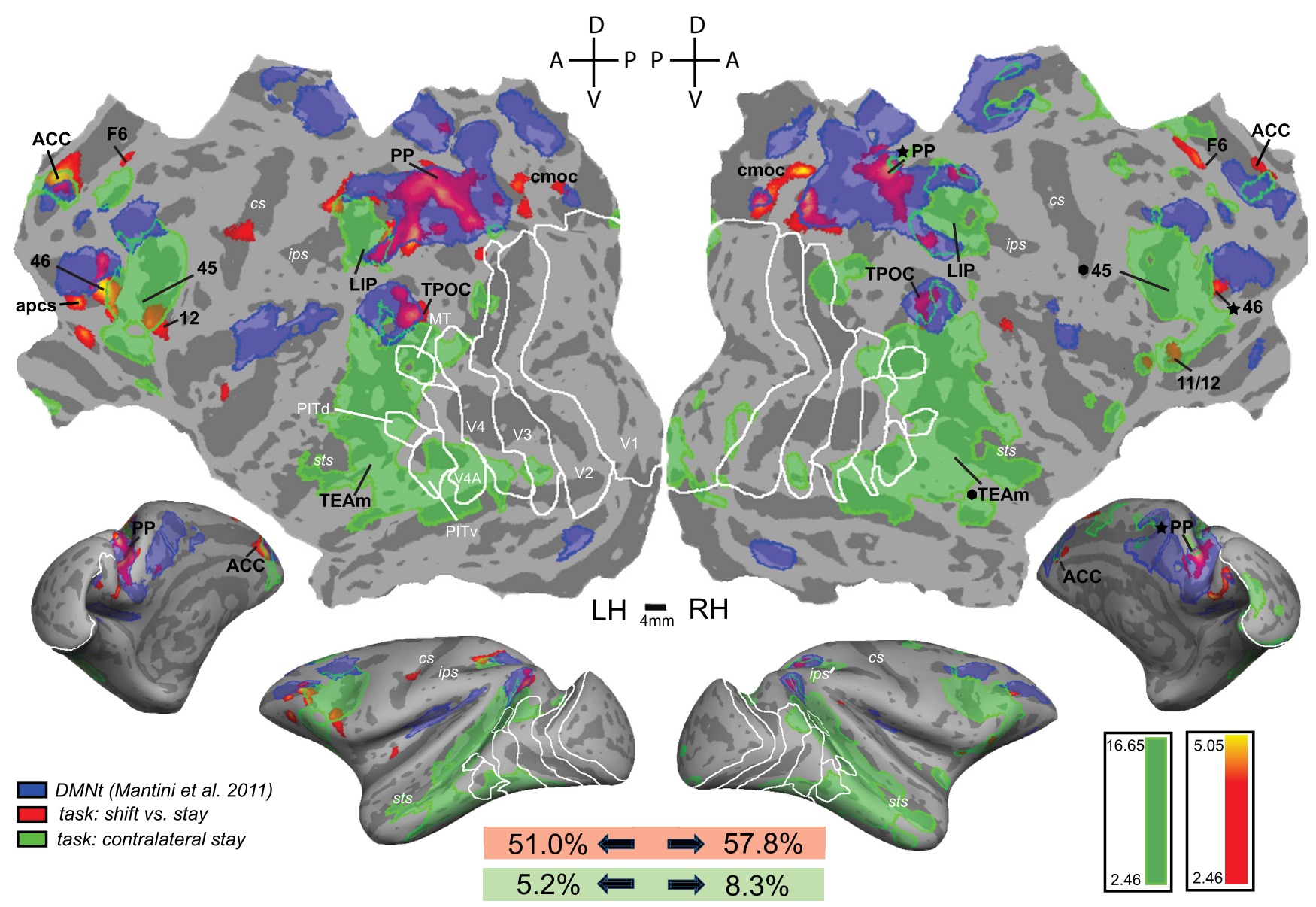

Figure 2. Shift and contralateral modulation of attention compared with the monkey DMN. Inflated (bottom, medial-parietal and lateral view) and flattened (top) surfaces of the F99 monkey brain showing data of the mixed-effects group analysis (3 monkeys), for shifting (hot color, with scalebar) and contralateral attention (green transparent color), both compared with the probabilistic monkey DMN (blue) (Mantini et al., 2011). Task-related data are shown at uncorrected level (MFX) but are present at corrected level (FWE, $p<0.05$ ) in the FFX. Numbers indicate percent overlap of voxels activated for shifting (red box), and contralateral attention (green box), with the DMN (LH and RH). Retinotopic outlines (white, $0.25^{\circ}-12.25^{\circ}$ eccentricity) are from Janssens et al. (2014). D, Dorsal; A, anterior; V, ventral; P, posterior. Sulci: i.p., Intraparietal; c, central; st, superior temporal. PP, Posterior parietal; apcs, anterior principal sulcus; PITd/v, posterior inferotemporal dorsal/ventral.

coding stay-left (right hemisphere, Fig. 3I) and stay-right (left hemisphere, Fig. 3J).

In the shift-selective foci, however, the shift conditions showed significantly smaller deactivations than all other conditions, explaining the shift selectivity of these voxels (Fig. 3C, especially $G$ ). Second, this way of displaying the raw data also revealed that all conditions on average peaked at $0 \mathrm{~ms}$ in the shift-selective foci (Fig. $3 G$ ), similar to the DMN foci (Fig. $3 H$ ), but not in the stay-selective foci (Fig. $3 I, J)$. This peak represents the time point of the expected stimulus change (feature change) in two-thirds of all trials (i.e., the shift and the stay, but not the null events). Consequently, this signal was not condition specific but inherent to the regularity of the trial structure in this experiment, where conditions changed every $2250 \mathrm{~ms}$ on average. When comparing the raw time courses against the moving average baseline (Fig. $3 H$ ) within all DMN ROIs (as listed in Table 1), this confirmed the overall deactivation pattern. Remarkably, these completely independently defined DMN-ROIs showed less deactivation for the shift compared with the stay conditions at $4 \mathrm{~s}$ after a stimulus change (Fig. $3 \mathrm{H}$, bar plot inset; $F_{(1,11)}=112.8 ; p<0.0001,2 \times 2$ ANOVA with factors conditions (shift, stay) $\times$ direction of attention (left, right)). Thus, the DMN ROIs were shift-selective. Finally, to estimate the similarity of the average raw time course patterns of shift and DMN ROIs (Fig. $3 G, H$ ), we computed the cross-correlation of both patterns across all conditions and time points. Shift and DMN time course patterns showed a high cross-correlation $\left(\mathrm{R}_{\text {shift/DMN }}=0.86, p<0.0001, t\right.$ test $)$; this was not the case for the stay ROIs $\left(\mathrm{R}_{\mathrm{DMN} / \mathrm{stayL}}=0.029, p=0.83 ; \mathrm{R}_{\mathrm{DMN} / \mathrm{stayR}}=0.17, p=\right.$ 0.20 ). This result cannot be explained by the general autocorrelation of the raw time course signal as the latter should be equally present across shift, stay, and DMN ROIs. Hence, the shiftselective regions fully complied with the definition of the DMN.

\section{Shift and stay networks compared with commonly used DMN definitions}

The DMN can be defined using several criteria (Karahanoğlu and Van De Ville, 2015). Hence, do our results also hold true using other commonly used DMN definitions, such as those based on (1) ICA (DMNic) (Moeller et al., 2009; Hutchison et al., 2011; Mantini et al., 2013); (2) seeding in medial posterior cingulate cortex (mPCC, DMNseed) (Vincent et al., 2007; Margulies et al., 2009; Teichert et al., 2010; Mantini et al., 2011; Hutchison and Everling, 2012); and (3) task-related deactivations (same as Fig. 2, DMNt)? To test this at group and individual levels, we also acquired resting state data from each animal while awake and fixating. It has to be noted that these different definitions of the DMN yield a set of core regions which are not exactly identical (Hutchison and Everling, 2012), and their convergence can be 


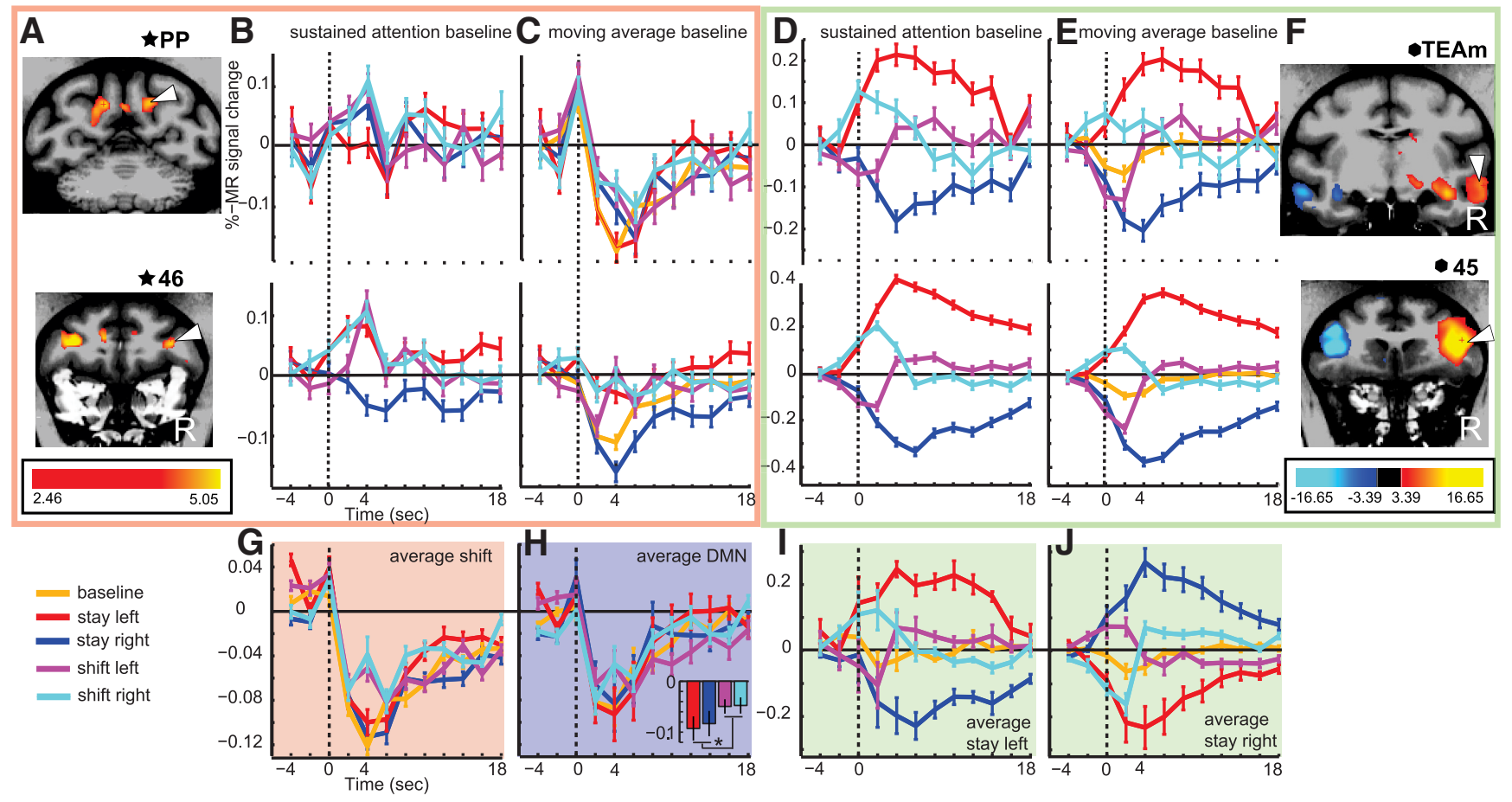

Figure 3. Raw time courses of shift, stay, and DMN ROls. $\boldsymbol{A}, \boldsymbol{F}$, Coronal sections with activations of the group $(n=3)$ for shift versus stay ( $\boldsymbol{A}$, same as hot color in Fig. 2 ), and stay left versus stay right $(\boldsymbol{F}$, hot color same as green in RH in Fig. 2) are shown in F99 space. Data are from the group mixed-effects analyses $(n=3)$. $\boldsymbol{B}-\boldsymbol{E}$, Raw time courses of these example shift $(\boldsymbol{B}, \boldsymbol{C})$ and stay $(\boldsymbol{D}, \boldsymbol{E})$ ROIs. $\mathbf{G}-\boldsymbol{J}$, Average time courses are plotted for all shift $(\boldsymbol{G})$, stay $(\boldsymbol{I}, \boldsymbol{J})$, and DMN ROls $(\boldsymbol{H})$. All ROls are listed in Table 1. Figure represents percent MR signal change of each condition against a sustained attention baseline $(\boldsymbol{B}, \boldsymbol{D})$ compared with a moving average baseline $(\boldsymbol{C}, \boldsymbol{E}, \boldsymbol{G}-\boldsymbol{J})$, at the respective local maxima ( $2 \mathrm{~mm}$ sphere). Dotted lines indicate event onset. Raw time courses are extracted from an equal number of runs across animals $(n=3, F F X)$. Error bars indicate the SEM across trials. $\boldsymbol{H}$, Shifts were significantly different from stay events $\left(F_{(1,11)}=112.8\right)$. ${ }^{*} p<0.0001$ (repeated-measures ANOVA). Shifts (shift, stay) $\times$ (left/right), summarized by the bar plot inset representing data values at $4 \mathrm{~s}$, and the respective SEs across ROls. Shift left and shift right were also significantly different from the null events/baseline $(p<0.005$, paired $t$ test).

inspected in Figure $4 A$, whereas their overlap with the respective shift and stay networks in the group and single monkeys is reported in Figure $4 B$.

To compare the overlap between the network activated for attention shifts with the group-level $(N=3)$ and monkey-specific DMNs, we first applied an ICA on the resting-state data of each individual by means of spatial ICA using the GIFT toolbox (Hutchison et al., 2011; Mantini et al., 2013). Spatial ICA extracts maximally independent patterns of coherent fMRI activity (Calhoun et al., 2001). We subsequently identified the independent component that correlated best with the monkey DMNt (Mantini et al., 2011) (Fig. 2, blue) for each subject (M13, $R^{2}=0.21$; M24, $R^{2}=0.27$; $35, R^{2}=0.35$ ) and for the group (DMNic, $\left.R^{2}=0.26\right)$. The mean stability index for these DMN components was 0.96 ( $\pm 0.03 \mathrm{SD}$ ) within the single monkeys and 0.81 for the group (computed by reiterating the ICA 10 times using the ICASSO toolbox; see Materials and Methods) (Himberg et al., 2004), indicating that the obtained clusters were consistent across multiple ICA runs. Group results of DMNic are displayed in Figure $4 A$ (purple overlay; for the volume display, see Fig. $5 B$ ). To further validate our DMN results with respect to previous studies using a seeding approach (Vincent et al., 2007; Margulies et al., 2009; Teichert et al., 2010; Mantini et al., 2011; Hutchison and Everling, 2012), we placed a seed (2 mm sphere) in medial posterior parietal cortex area 23/31 (Vincent et al., 2007; Margulies et al., 2009; Hutchison and Everling, 2012) as indicated by Figure $4 A$ (light-blue dotted circle; see Fig. $5 C$, transverse sections). Importantly, this seed was located outside shift-selective areas (Fig. $4 A$, hot color). Comparison of the three DMN definitions (DMNt, DMNic, and DMNseed) in Figure $4 A$ highlighted common core regions located in $\mathrm{cmoc}$, posterior parietal cortex (including areas 31/V6A/V6/PGm), and spreading into the intraparietal sulcus (including $\mathrm{PEa}$ ), bilateral posterior STS regions termed TPOC, caudal area 46, and the FEF (only visible in the volume of DMNic, Fig. $5 B$, transverse slices $-16 / 16$, respectively), but not the ACC. In most of these core regions (except FEF), shift-selective voxels overlapped with DMN voxels (Fig. $4 A$, blue, cyan, and purple overlap with hot colors). Finally, we obtained a fourth DMN-like map in the same animals by contrasting fixation with visual stimulation, obtained in independent localizer scans for identifying the cortical representations of the shapes used in the attention task, and displayed in the volume of Figure $5 D$. Figure $4 B$ summarizes the percent overlap of shift (Figs. 2, 4A, hot color), and stay-selective voxels (Fig. 2, green), with each of the four DMN definitions for the group and for the individual monkeys.

It has to be noted that the DMNt data in Figures 2 and $4 B$ were obtained from a meta-analysis, including M13 and 9 other animals (Fig. 5A, volume sections). The other three DMNs (DMNic, DMNseed, and DMN Fix vs Visual) were individually defined within each of our subjects. Using the data across these three monkey-specific DMNs, we observed an average overlap of $62.06 \%$ shift (DMN voxels vs $13.37 \%$ stay) DMN voxels. The shift overlap with the DMN was significantly different from an overlap calculated based on a chance distribution of the shift voxels $(p<$ 0.001 ), as determined by randomly shuffling locations of shift voxels (see Definition of overlap: Shift voxels and DMN voxels). This was not the case for the stay-DMN overlap, except when the DMNseed definition was used, which revealed an overlap marginally above chance level (see Fig. $4 B$, light blue bars). This indicates that, for the individually defined DMNs, virtually 


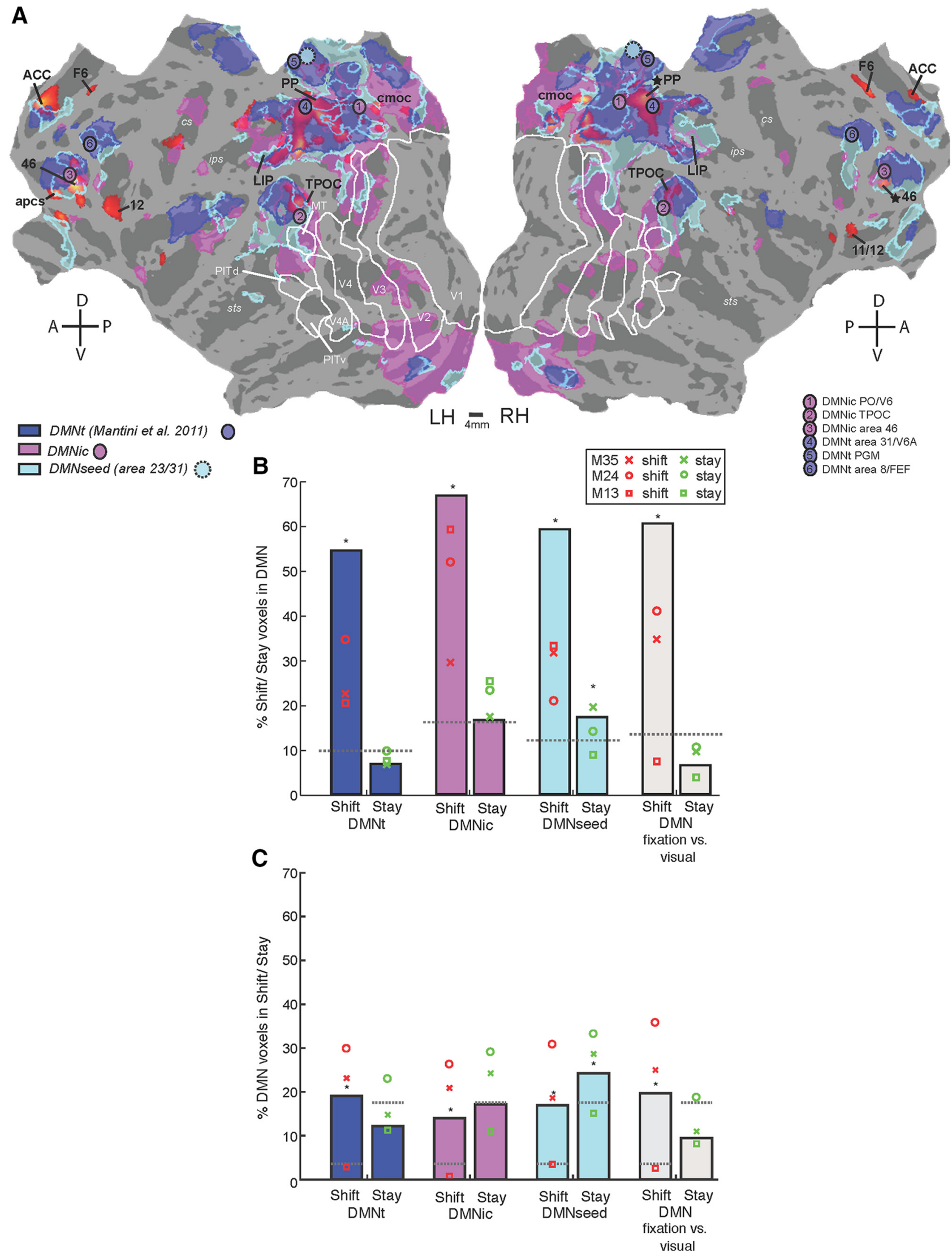

Figure 4. Task-related shift network compared with currently existing definitions of the DMN. A, (1) DMNt (dark blue): meta-analysis of task-related deactivations (Mantini et al., 2011), corresponding to the original definition used in human (Raichle et al., 2001); (2) DMNic (purple): ICA (IC is spatially best correlating with 1); (3) DMNseed (light blue): defined by seeding in PCC node (area 31/23) indicated on the flat map (dotted circle). DMNvis is not shown on the figure to prevent overcrowding. Numbered circles represent the location of ROls (local maxima), of each DMN in the corresponding color, that entered the cross-correlation analysis in Figure 6 (also listed in Table 1). For labels and flat map, same conventions as in Figure 2. (Figure legend continues.) 
A

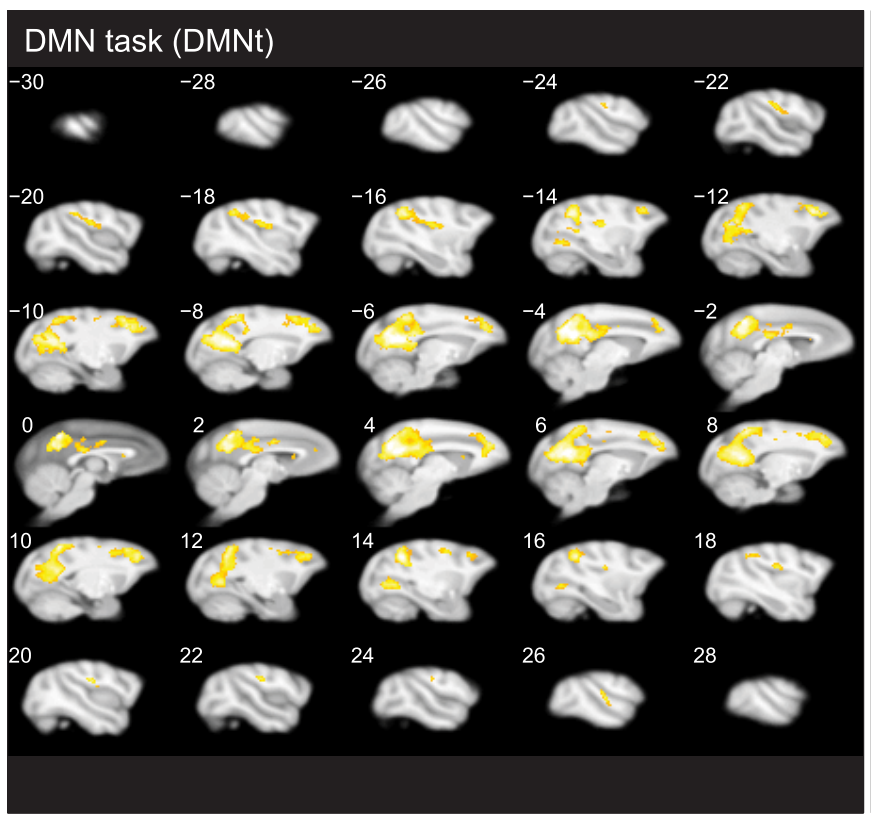

C

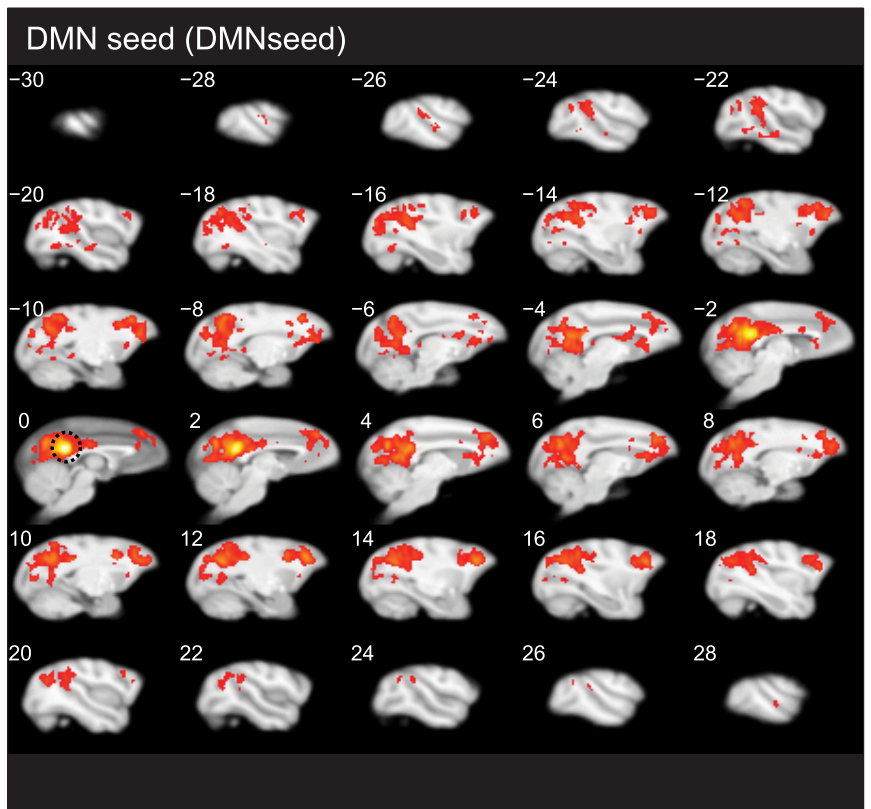

B

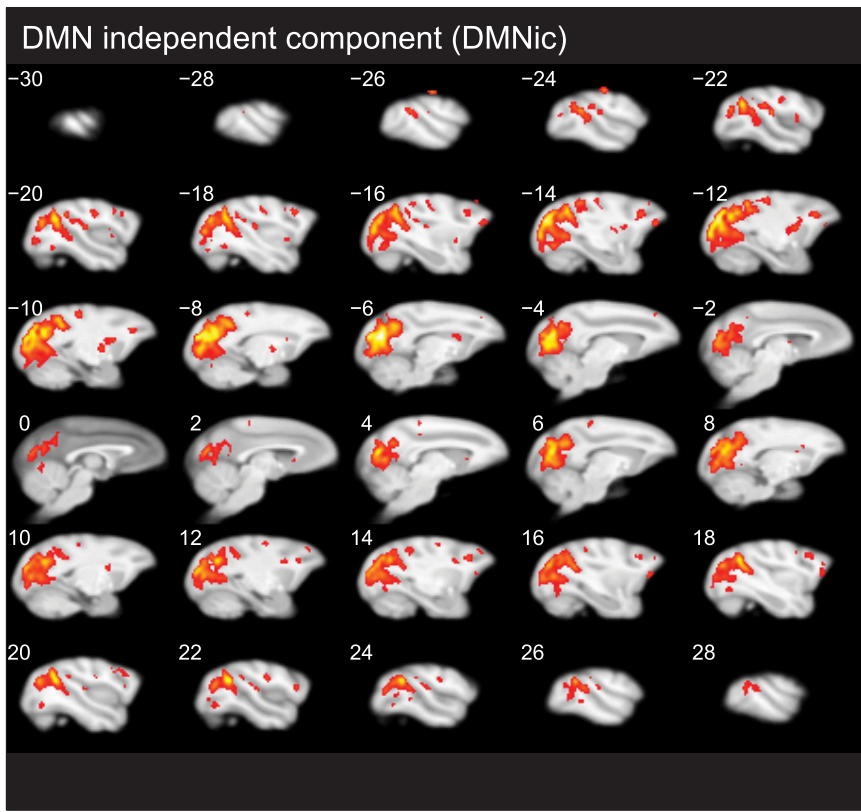

D

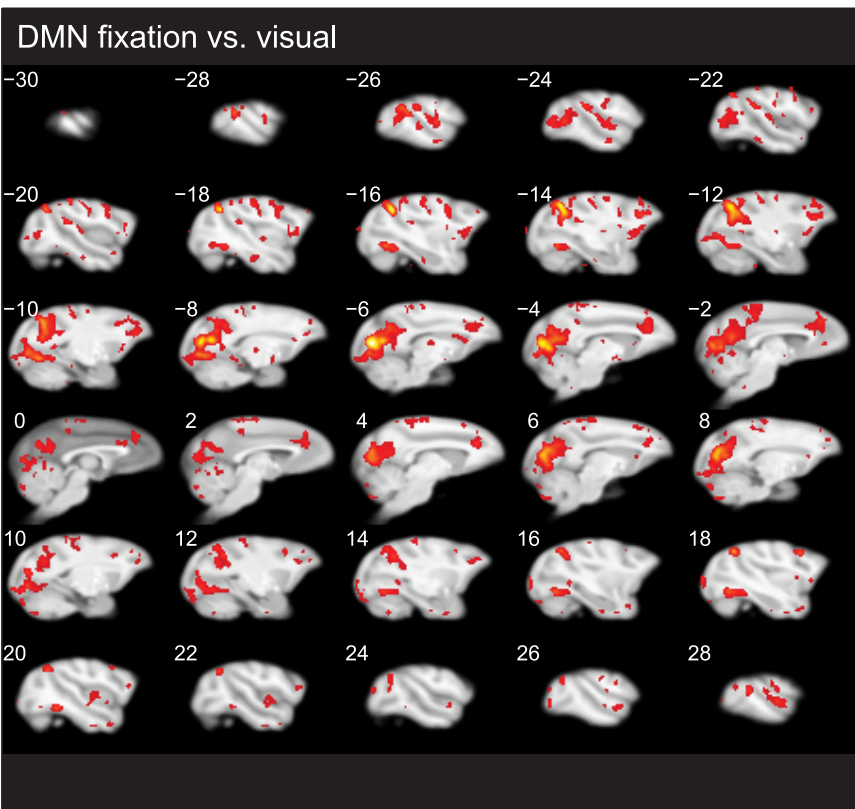

Figure 5. Transverse volume sections of four DMN definitions as displayed in Figure 4A. A, DMNt, as defined by Mantini et al. (2011) in a meta-analysis of task-related deactivations across 15 experiments (at threshold 8 of 15 experiments). B, C, DMNs obtained from the resting state scans across the 3 animals (awake while fixating). $B$, DMNic, defined by ICA at threshold $z=1$ (Hutchison et al., 2011). C, DMNseed, defined by seeding in medial PCC node (border of area 23/31, seed position indicated on slice 0 with dotted circle) (Vincent et al., 2007; Hutchison et al., 2011), FFX, thresholded at FWE $(p=0.05)$. D, DMN fixation versus visual obtained from an independent stimulus localizer dataset, FFX across all sessions of the 3 monkeys, thresholded at FWE $(p=0.05)$, contrasting fixation with visual stimulation (same stimuli and eccentricity as shown during selective attention task). fMRI data analysis.

(Figure legend continued.) B, Percent overlap of shift-selective (contrast 3) and stay-selective (contrast 1 and 2) voxels, with each version of the DMN and ( $C$ ) percent overlap of the DMN with the shift- and stay-selective voxels for the group (bars, $N=3$ ) and individual monkeys (red represents shift activations; green represents stay activations). Same conventions as in Figure 2 (for each contrast), and $\boldsymbol{A}$ (for colors). Rightmost plot represents task-related deactivations in the stimulus localizer data of the same animals contrasting the fixation-only condition versus visual stimulation (DMN Fixation vs Visual). Volume sections of the different DMNs are displayed in Figure 5. Dashed lines indicate the chance level overlap, as determined by randomly shuffling of voxels $(1000 \times)$ across the gray matter surface. ${ }^{*} p<0.001$. two-thirds of the shift voxels were located within the DMN, whereas stay-selective voxels were mainly located outside the DMN.

Conversely, we also compared the overlap of DMN and shift voxels over the total number of DMN voxels (Fig. 4C). On average (across all DMN definitions), $17.43 \%$ of the DMN voxels overlapped with shift voxels $(\mathrm{DMNt}=19.11 \%, \mathrm{DMNic}=13.99 \%$, DMNseed $=16.97 \%$, DMN-fixation-vs-visual $=19.67 \%$, average chance overlap of DMN and shift voxels over the total number of DMN voxels: $3.58 \%$ ). This suggests that, whereas most of the shift voxels are located within core DMN regions, only a fraction of the 
entire DMN is specifically recruited for computing one specific type of cognitive shift, namely, spatial attention shifts. As the repertoire of possible cognitive shifts is exceedingly large, our findings are entirely in line with the expectation that only a relatively small fraction of the DMN will overlap with the substrate processing shifts in spatial attention. In contrast, the average overlap of the DMN and the stay voxels relative to the total DMN was below chance (average $=15.75 \%$, chance overlap $=17.57 \%$, $\mathrm{DMNt}=12.15 \%, \mathrm{DMNic}=17.17 \%$, DMNseed $=24.28 \%$, DMN-fixation-vs-visual $=9.42$ ).

We also examined the overlap of the shift and stay activations with a monkey-specific frontoparietal network (FPN) derived from the ICA analysis (see Materials and Methods). We found a significant overlap of FPN and shift voxels over the total number of FPN voxels (group 25.86\%, chance level 6.83\%). Despite this, the overlap of the shift regions with the DMN (62.06\%) was larger than its overlap with the FPN $(25.86 \%)$. In contrast, the overlap of the stay regions (group 13.37\%, chance level 6.83\%) with the DMN, although significant, was comparable with its overlap with the frontoparietal network (14.01\%). Furthermore, overlap with the DMN (shift 62.06\%; stay 13.37\%) better separated the shift and stay regions compared with FPN (shift 25.86\%; stay $14.01 \%)$.

\section{Functional connectivity and unsupervised clustering of DMN shift and stay regions at rest}

Next, we performed a cross-correlation analysis on resting state data acquired in each animal, thereby focusing on the nodes of the default mode, shift and stay networks (for the definitions of DMN, shift, and stay nodes, see Table 1). We hypothesized that DMN and shift areas should show more highly correlated spontaneous fMRI activity compared with DMN and stay areas. As can be observed in the cross-correlation matrix (Fig. 6), posterior nodes within the shift network correlated highly with the posterior DMN nodes $(r=0.51, p<0.001)$, and even with the entire $\operatorname{DMN}(r=0.45, p=0.0018)$. This was not the case for the stay nodes (both $r=0.16, p=0.06$ ). Between the DMN and stay network, area LIP was the main node revealing high correlations with the DMN $(r=0.45, p=0.004)$. It needs to be noted, however, that LIP showed both shift and stay signals in the covert attention task (Caspari et al., 2015) and is most likely a central hub for both. Noteworthy is TPOC within the DMN located in the posterior STS, which correlated significantly with most posterior shift ROIs $(r=0.38, p \ll 0.001)$. Although functional connectivity tends to decrease with interregional distance (Salvador et al., 2005; Honey et al., 2009), the pattern of the correlation matrix cannot be explained based on distance alone because frontal shift regions were significantly correlated with posterior DMN areas. For example, the anterior principal sulcus, the most frontal node of the shift network, significantly $(p<0.001)$ correlated with bilateral PO/V6 $(r>0.3)$ of the DMN. Also, right FEF, as part of the DMN, was significantly $(p<0.001)$ correlated with left TPOC and cmoc $(r>0.22)$ of the shift network. Unsupervised, hierarchical cluster analysis applied to the correlation matrix, using the average linkage algorithm (Everitt et al., 2001), confirmed that shift and DMN nodes were intermingled within one cluster, which split into posterior and anterior clusters (Fig. 7). The only exception within the posterior DMN/shift cluster was LIP, which belongs to the stay network (but see above), and left FST, that clustered apart. Exceptional shift nodes were areas $11 / 12$, somatomotor cortex, and area F6, as they were not correlated with the rest of the shift ROIs $(r=1.3, p=0.05)$. These formed clusters among the stay ROIs (Fig. 7).

\section{Discussion}

We used an attention paradigm comparing activity during task epochs requiring either profound or small cognitive shifts. We demonstrated that fMRI activations induced by shifts of attention, and not by sustained attention, largely coincide with core nodes of the monkey DMN. Crucially, when these DMN regions were independently defined, they showed significant shift selectivity. Also, the average raw fMRI time courses of independently defined DMN and shift nodes were highly correlated. Unexpectedly, the regions involved in shifting attention showed substantial deactivations for all task conditions relative to the raw baseline fMRI signal, which is a hallmark of the DMN. Finally, a functional cross-correlation analysis among core nodes of the default mode, shift and stay networks, using independent resting state data acquired in the same subjects, revealed high functional correlations between all posterior regions of the shift network and the DMN. This provides additional evidence that attention shift and DMN-ROIs share functional properties during task performance (Fox and Raichle, 2007). Our results were independent of the exact DMN definition because four commonly used versions of the DMN (Hutchison and Everling, 2012), based on ICA, seeding, task-related deactivations from a meta-analysis, and stimulusdriven deactivations (in the same individuals), revealed highly similar results (Mantini and Vanduffel, 2013). We propose that cognitive shifting, in general, is one of the evolutionary preserved functions of the DMN, which may also explain its involvement in introspective behaviors and a large number of brain pathologies.

\section{Segregation between anterior and posterior shift and DMN ROIs?}

Whereas posterior shift-selective regions, such as the caudal $(\mathrm{cmoc})$, medial (posterior parietal), and lateral parietal (TPOC) regions showed virtually complete overlap with the DMN, convergence in frontal regions (ACC, area 46, areas 11/12, F6) was not complete (Figs. 2, 4A). Segregation between frontal and parietal shift-selective ROIs was also apparent in the functional correlation matrix (Fig. 6). Frontal shift regions (especially areas F6, somatomotor cortex, and areas 11/12) correlated less with the rest of the shift ROIs, and all DMN ROIs. The only exception was area 46, also included within the DMN (Mantini et al., 2011). Potentially, some of the anterior shift regions in monkey might be involved in cognitive control during task performance, rather than exhibiting purely DMN or shift-related activity. Cognitive control functions have been linked to activity in monkey ACC (Brown and Braver, 2005; Quilodran et al., 2008; Rushworth and Behrens, 2008), and also area 46 (Ridderinkhof et al., 2004; Rossi et al., 2007). This might explain why both ACC and area 46 converged at the same time with DMN, shift- and stay-selective regions (Fig. 2), indicating a common involvement across networks. Area 12 in monkey lateral prefrontal cortex exerted cognitive control during a complex cognitive set shifting task (Nakahara et al., 2002) and during goal-directed action (Borra et al., 2011). Similarly, presupplementary motor area (F7) was shown to regulate goal-directed behavioral control (Isoda and Hikosaka, 2007; Nachev et al., 2008). In humans, recent evidence suggested that the DMN couples to the frontoparietal control network during goal-directed cognition (Spreng et al., 2010). It is possible that also in monkeys the control network couples to the DMN/shift network, to correctly instantiate a challenging rule-driven cognitive shift.

Posterior and anterior DMN structures may be functionally segregated, as has been suggested for the human DMN using ICA (Damoiseaux et al., 2006; Cassidy et al., 2016) or task-based fMRI (Whitfield-Gabrieli et al., 2011). Also, seeding within human PCC 


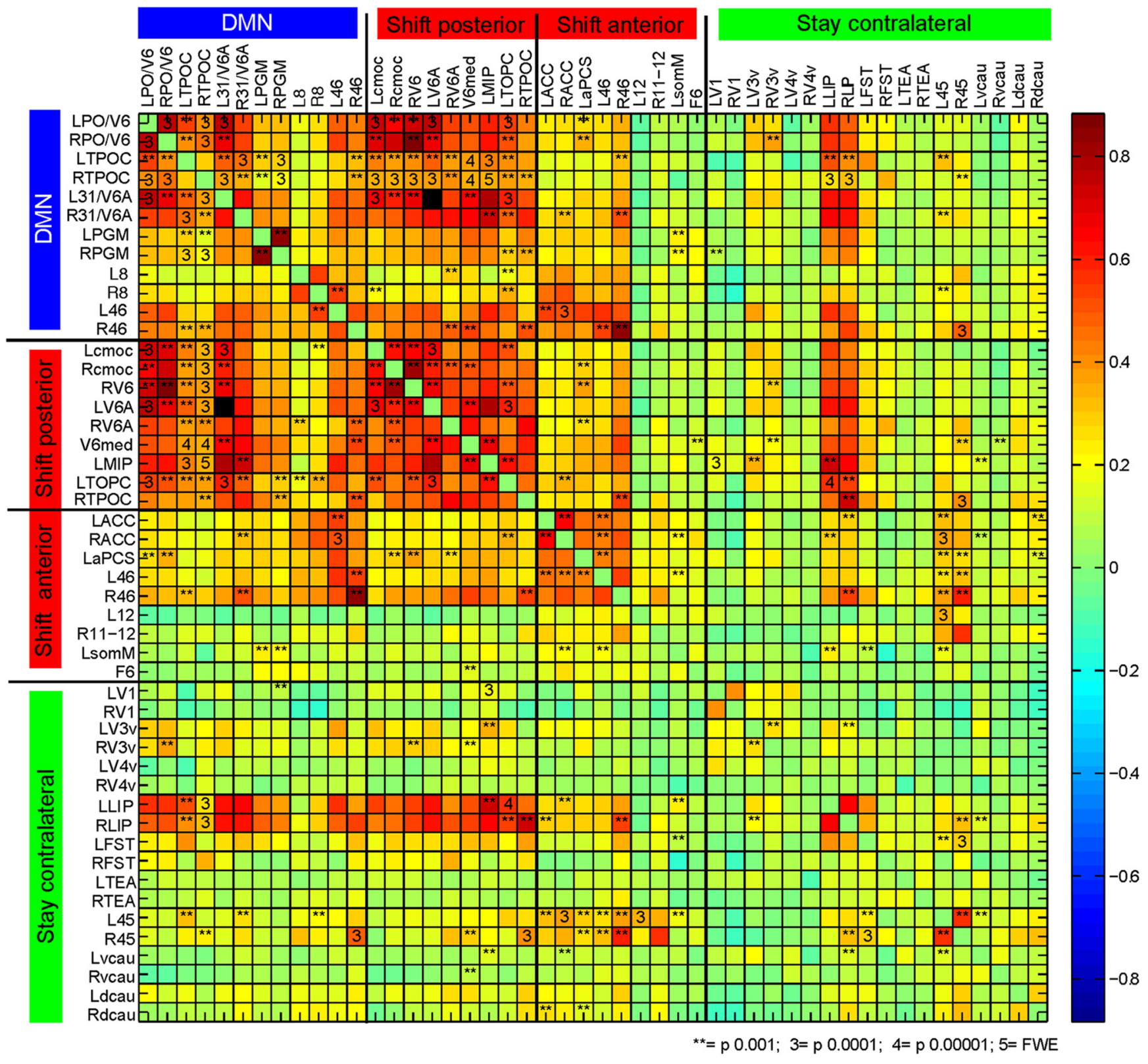

Figure 6. ROI cross-correlation analyses between nodes of task-related shift and stay networks (Caspari et al., 2015) and core nodes of the DMN. Significant correlation between DMN and posterior shift ROls. Nodes were defined as $2 \mathrm{~mm}$ radius spheres around local maxima of each R0I (Table 1). Correlation values are indicated with color code (red represents high correlation; blue represents anticorrelation), representing the average correlation across all sessions of all animals. Significances are computed from a MFX across sessions ( $n=6,2$ per animal, at $p<0.001)$. Black squares in the matrix have the same stereotactic coordinate; hence, no value was calculated. ${ }^{* *} p<0.001 .{ }^{3} p<0.0001$. ${ }^{4} p<0.00001$. ${ }^{5}$ FWE $(p=0.05)$. Same conventions as in Figures $2-4$. L, Left; R, right; $\mathrm{PO}$, parieto-occipital.

reveals more consistent DMN locations than seeding in $\mathrm{mPFC}$ (Greicius et al., 2003). Although mPFC and PCC are highly connected and interacting (e.g., during working memory encoding) (Hampson et al., 2006), both show anticorrelations with a distinct set of areas, and both nodes interact with a different set of task-positive networks (Uddin et al., 2009).

\section{Extent of the DMN compared with the spatial} shift-selective network

Overall, many shift voxels (on average 64\%, across the four DMN definitions) recruited regions within the DMN. Conversely, the percentage of individual DMN voxels selective for spatial attention shifts was much lower (on average 16.2\%). In case cognitive shifting is one of the defining DMN properties, as we propose, this result can be expected because we tested only one of many possible types of cognitive shifts. Also in humans, shifts between mental events, future and past thoughts, between feelings of oneself or another, the internal and external bodily state or internally and externally directed attention, recruit different units of the DMN, which may also contribute to the existence of different definitions (Buckner et al., 2008) or subdivisions (Andrews-Hanna et al., 2010) of the DMN. The richer the set of cognitive shifts, for example, when averaging across unconstrained mental processes, or during meta-analyses pooling the activity induced by a wide variety of cognitive shifts, the more DMN voxels might be identified. For instance, emotional, social, and self-referential DMN functions in humans are more often assigned to anterior DMN regions such as mPFC (D’Argembeau et al., 2005; Gilbert et al., 


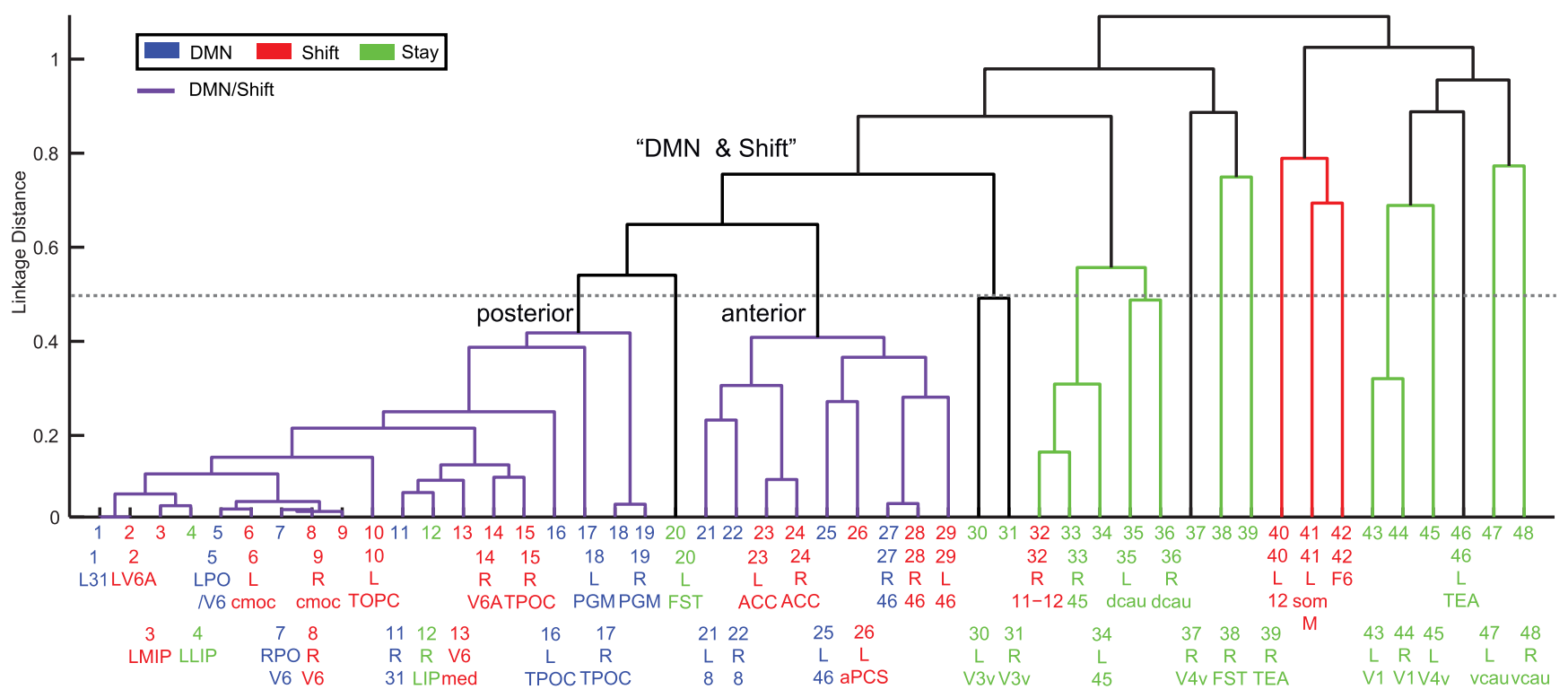

Figure 7. Clustering across stay, shift, and DMN ROIs. Dendrogram represents the unsupervised clustering of all the ROls from the correlation matrix in Figure 6 based on their functional correlation values, using the average linkage algorithm (Everitt et al., 2001; Mantini et al., 2011). Clusters with a linkage distance $>0.5$ are colored according to whether they include stay (green), or shift (red) seeds, or a mixture of shift and DMN seeds (purple).

2006; Mitchell et al., 2006). Visuospatial imagery, episodic memory retrieval, and anticipatory attention shifts, on the other hand, are assigned to posterior DMN regions, including PCC (Small et al., 2003; Lundstrom et al., 2005; Cavanna and Trimble, 2006).

\section{How could cognitive shifting be implemented by the DMN?}

Many cognitive processes that have been associated with DMN function can be typified as having frequent cognitive shifts: shifting from one thought to another during mind wandering, autobiographical memory, thinking about your own thoughts and emotions (meta-cognition), thinking about other people's thoughts, emotions, and motivations (theory-of-mind), thinking about and planning your own future, shifting your focus of attention while monitoring the external world, social working memory, and story comprehension. Therefore, we propose that cognitive shifting, in general, is one of the evolutionary preserved functions of the DMN, which may explain its involvement in introspective behaviors and a large number of brain pathologies.

DMN and shift regions show an unexpectedly similar pattern of deactivation (Fig. 3G,H). Mechanistically, a sudden shift may be accomplished through a release of inhibition (Sauseng et al., 2005), leading to a negative fMRI signal being attenuated. Release of inhibition might be energetically the most efficient manner to quickly allocate resources enabling rapid cognitive events. At first glance, our data seem at odds with the lower activity levels of posterior cingulate neurons within the presumptive DMN during an attention and working-memory task compared with rest (Hayden et al., 2009). However, in the working memory condition of that study, a clear tonic release of inhibition was observed upon appearance of a brief, spatially unpredictable memory cue. Likely, this triggered a sudden shift in spatial attention, corroborating the present results. Similarly, single neurons recorded in area $7 \mathrm{a}$, converging with monkey TPOC, are suppressed during covert attention to the visual periphery (Steinmetz et al., 1994). Neurons in area $7 \mathrm{a}$ also fired when the locus of attention shifted during the trial, showing an enhancement for a matched stimulus (Rawley and Constantinidis, 2010), and they were influenced by covert shifts of attention away from the point of fixation (Stein- metz and Constantinidis, 1995). Area 7a neurons/monkey TPOC show thus similar properties as DMN and shift regions: DMNlike deactivations together with activation during attention shifts. Together with the average time course of the monkey DMN and shift regions, this is entirely in line with the sentinel hypothesis of the DMN (Buckner et al., 2008).

A similar pattern of deactivation has previously been reported for the right human temporoparietal junction/supramarginal gyrus, showing deactivations during visual search (requiring many shifts across the visual hemifield), and activations during target detection (Shulman et al., 2003, 2007; Anticevic et al., 2010; Gillebert et al., 2012). Parts of this ventral supramarginal gyrus showed a significant BOLD-target detection correlation and a strong deactivation with respect to a passive viewing baseline (Shulman et al., 1997, 2007). In human, this region is heterogeneous (Mars et al., 2012a; Igelström et al., 2015), and at least a portion belongs to the DMN (Mars et al., 2012b).

Human intracranial recordings also showed suppression of DMN gamma band activity during a visual search task (Ossandón et al., 2011). The more suppression of the DMN, the faster targets were detected. Conversely, the DMN was more active when the subject shifted attention for longer periods during the search task. Another study also showed increased activity in human DMN areas, which correlated with faster reaction times when unpredictable stimuli had to be detected, requiring sudden attention shifts (Hahn et al., 2007). Core DMN areas, such as the PCC and mPFC, are activated during anticipatory allocation of attention (Small et al., 2003). Finally, core and medial temporal lobe subnetworks of the DMN are engaged during profound cognitive shifts in humans (Crittenden et al., 2015).

These findings highlight the transient and dynamic nature of the DMN (Ossandón et al., 2011) and its potential involvement in cognitive shifts. Rapid automatic shifts of attention for detecting predators and unexpected, possibly life-threatening events are fundamental for survival of the primate species. Our findings add evidence in favor of the hypothesis that the computation of cognitive shifts in general might be a major driving factor of the DMN. Obviously, the present dataset does not preclude that other functions in 
addition to cognitive shifting are carried by the DMN. It is noteworthy, however, that most of the functions previously attributed to the DMN can be explained by the cognitive shifting theory. Future studies are also required to investigate whether variants of "cognitive" shifting also activate the DMN of other mammals, including rodents.

\section{References}

Abou-Elseoud A, Starck T, Remes J, Nikkinen J, Tervonen O, Kiviniemi V (2010) The effect of model order selection in group PICA. Hum Brain Mapp 31:1207-1216. CrossRef Medline

Andrews-Hanna JR, Reidler JS, Sepulcre J, Poulin R, Buckner RL (2010) Functional-anatomic fractionation of the brain's default network. Neuron 65:550-562. CrossRef Medline

Anticevic A, Repovs G, Shulman GL, Barch DM (2010) When less is more: TPJ and default network deactivation during encoding predicts working memory performance. Neuroimage 49:2638-2648. CrossRef Medline

Arsenault JT, Nelissen K, Jarraya B, Vanduffel W (2013) Dopaminergic reward signals selectively decrease fMRI activity in primate visual cortex. Neuron 77:1174-1186. CrossRef Medline

Berger HJ, Aerts FH, van Spaendonck KP, Cools AR, Teunisse JP (2003) Central coherence and cognitive shifting in relation to social improvement in high-functioning young adults with autism. J Clin Exp Neuropsychol 25:502-511. CrossRef Medline

Borra E, Gerbella M, Rozzi S, Luppino G (2011) Anatomical evidence for the involvement of the macaque ventrolateral prefrontal area $12 \mathrm{r}$ in controlling goal-directed actions. J Neurosci 31:12351-12363. CrossRef Medline

Brown JW, Braver TS (2005) Learned predictions of error likelihood in the anterior cingulate cortex. Science 307:1118-1121. CrossRef Medline

Buckner RL, Carroll DC (2007) Self-projection and the brain. Trends Cogn Sci 11:49-57. CrossRef Medline

Buckner RL, Andrews-Hanna JR, Schacter DL (2008) The brain's default network. Ann N Y Acad Sci 1124:1-38. CrossRef Medline

Calhoun VD, Adali T, Pearlson GD, Pekar JJ (2001) A method for making group inferences from functional MRI data using independent component analysis. Hum Brain Mapp 14:140-151. CrossRef Medline

Caspari N, Janssens T, Mantini D, Vandenberghe R, Vanduffel W (2015) Covert shifts of spatial attention in the macaque monkey. J Neurosci 35:7695-7714. CrossRef Medline

Caspari N, Arsenault JT, Vandenberghe R, Vanduffel W (2017) Functional similarity of medial superior parietal areas for shift-selective attention signals in humans and monkeys. Cereb Cortex. Advance online publication. Retrieved May 4, 2017. CrossRef Medline

Cassidy CM, Van Snellenberg JX, Benavides C, Slifstein M, Wang Z, Moore H, Abi-Dargham A, Horga G (2016) Dynamic connectivity between brain networks supports working memory: relationships to dopamine release and schizophrenia. J Neurosci 36:4377-4388. CrossRef Medline

Cavanna AE, Trimble MR (2006) The precuneus: a review of its functional anatomy and behavioural correlates. Brain 129:564-583. CrossRef Medline

Correa N, Adali T, Calhoun VD (2007) Performance of blind source separation algorithms for fMRI analysis using a group ICA method. Magn Reson Imaging 25:684-694. CrossRef Medline

Crittenden BM, Mitchell DJ, Duncan J (2015) Recruitment of the default mode network during a demanding act of executive control. eLife 4:e06481. CrossRef Medline

Cui X, Stetson C, Montague PR, Eagleman DM (2009) Ready.Go: amplitude of the fMRI signal encodes expectation of cue arrival time. PLoS Biol 7:e1000167. CrossRef Medline

Damoiseaux JS, Rombouts SA, Barkhof F, Scheltens P, Stam CJ, Smith SM, Beckmann CF (2006) Consistent resting-state networks across healthy subjects. Proc Natl Acad Sci U S A 103:13848-13853. CrossRef Medline

D’Argembeau A, Collette F, Van der Linden M, Laureys S, Del Fiore G, Degueldre C, Luxen A, Salmon E (2005) Self-referential reflective activity and its relationship with rest: a PET study. Neuroimage 25:616-624. CrossRef Medline

Daselaar SM, Prince SE, Cabeza R (2004) When less means more: deactivations during encoding that predict subsequent memory. Neuroimage 23: 921-927. CrossRef Medline

Ekstrom LB, Roelfsema PR, Arsenault JT, Kolster H, Vanduffel W (2009) Modulation of the contrast response function by electrical microstimulation of the macaque frontal eye field. J Neurosci 29:10683-10694. CrossRef Medline
Esposito F, Scarabino T, Hyvarinen A, Himberg J, Formisano E, Comani S, Tedeschi G, Goebel R, Seifritz E, Di Salle F (2005) Independent component analysis of fMRI group studies by self-organizing clustering. Neuroimage 25:193-205. CrossRef Medline

Everitt BS, Landau S, Leese M, Everitt BS, Landau S, Leese M (2001) Cluster analysis. London, England: Arnold.

Fox MD, Raichle ME (2007) Spontaneous fluctuations in brain activity observed with functional magnetic resonance imaging. Nat Rev Neurosci 8:700-711. CrossRef Medline

Friston KJ, Holmes AP, Poline JB, Grasby PJ, Williams SC, Frackowiak RS, Turner R (1995) Analysis of fMRI time series revisited. Neuroimage 2:4553. CrossRef Medline

Friston KJ, Stephan KE, Lund TE, Morcom A, Kiebel S (2005) Mixed-effects and fMRI studies. Neuroimage 24:244-252. CrossRef Medline

Genest C (1992) Vincentization revisited. Ann Statist 1137-1142. CrossRef

Gilbert SJ, Simons JS, Frith CD, Burgess PW (2006) Performance-related activity in medial rostral prefrontal cortex (area 10) during low-demand tasks. J Exp Psychol Hum Percept Perform 32:45-48. CrossRef Medline

Gillebert CR, Dyrholm M, Vangkilde S, Kyllingsbæk S, Peeters R, Vandenberghe R (2012) Attentional priorities and access to short-term memory: parietal interactions. Neuroimage 62:1551-1562. CrossRef Medline

Greicius MD, Krasnow B, Reiss AL, Menon V (2003) Functional connectivity in the resting brain: a network analysis of the default mode hypothesis. Proc Natl Acad Sci U S A 100:253-258. CrossRef Medline

Hahn B, Ross TJ, Stein EA (2007) Cingulate activation increases dynamically with response speed under stimulus unpredictability. Cereb Cortex 17:1664-1671. CrossRef Medline

Hampson M, Driesen NR, Skudlarski P, Gore JC, Constable RT (2006) Brain connectivity related to working memory performance. J Neurosci 26:13338-13343. CrossRef Medline

Hayden BY, Smith DV, Platt ML (2009) Electrophysiological correlates of default-mode processing in macaque posterior cingulate cortex. Proc Natl Acad Sci U S A 106:5948-5953. CrossRef Medline

Himberg J, Hyvärinen A, Esposito F (2004) Validating the independent components of neuroimaging time series via clustering and visualization. Neuroimage 22:1214-1222. CrossRef Medline

Honey CJ, Sporns O, Cammoun L, Gigandet X, Thiran JP, Meuli R, Hagmann P (2009) Predicting human resting-state functional connectivity from structural connectivity. Proc Natl Acad Sci U S A 106:2035-2040. CrossRef Medline

Hutchison RM, Everling S (2012) Monkey in the middle: why nonhuman primates are needed to bridge the gap in resting-state investigations. Front Neuroanat 6:29. CrossRef Medline

Hutchison RM, Leung LS, Mirsattari SM, Gati JS, Menon RS, Everling S (2011) Resting-state networks in the macaque at 7T. Neuroimage 56: 1546-1555. CrossRef Medline

Igelström KM, Webb TW, Graziano MS (2015) Neural processes in the human temporoparietal cortex separated by localized independent component analysis. J Neurosci 35:9432-9445. CrossRef Medline

Isoda M, Hikosaka O (2007) Switching from automatic to controlled action by monkey medial frontal cortex. Nat Neurosci 10:240-248. CrossRef Medline

Janssens T, Keil B, Farivar R, McNab JA, Polimeni JR, Gerits A, Arsenault JT, Wald LL, Vanduffel W (2012) An implanted 8-channel array coil for highresolution macaque MRI at 3T. Neuroimage 62:1529-1536. CrossRef Medline

Janssens T, Zhu Q, Popivanov ID, Vanduffel W (2014) Probabilistic and single-subject retinotopic maps reveal the topographic organization of face patches in the macaque cortex. J Neurosci 34:10156-10167. CrossRef Medline

Karahanoğlu FI, Van De Ville D (2015) Transient brain activity disentangles fMRI resting-state dynamics in terms of spatially and temporally overlapping networks. Nat Commun 6:7751. CrossRef Medline

Kolster H, Mandeville JB, Arsenault JT, Ekstrom LB, Wald LL, Vanduffel W (2009) Visual field map clusters in macaque extrastriate visual cortex. J Neurosci 29:7031-7039. CrossRef Medline

Leech R, Sharp DJ (2014) The role of the posterior cingulate cortex in cognition and disease. Brain 137:12-32. CrossRef Medline

Leite FP, Tsao D, Vanduffel W, Fize D, Sasaki Y, Wald LL, Dale AM, Kwong KK, Orban GA, Rosen BR, Tootell RB, Mandeville JB (2002) Repeated fMRI using iron oxide contrast agent in awake, behaving macaques at 3 tesla. Neuroimage 16:283-294. CrossRef Medline 
Li CS, Yan P, Bergquist KL, Sinha R (2007) Greater activation of the default brain regions predicts stop signal errors. Neuroimage 38:640-648. CrossRef Medline

Lu H, Zou Q, Gu H, Raichle ME, Stein EA, Yang Y (2012) Rat brains also have a default mode network. Proc Natl Acad Sci U S A 109:3979-3984. CrossRef Medline

Lundstrom BN, Ingvar M, Petersson KM (2005) The role of precuneus and left inferior frontal cortex during source memory episodic retrieval. Neuroimage 27:824-834. CrossRef Medline

Madore B, Glover GH, Pelc NJ (1999) Unaliasing by Fourier-encoding the overlaps using the temporal dimension (UNFOLD), applied to cardiac imaging and fMRI. Magn Reson Med 42:813-828. CrossRef Medline

Mandeville JB, Marota JJ (1999) Vascular filters of functional MRI: spatial localization using BOLD and CBV contrast. Magn Reson Med 42:591598. CrossRef Medline

Mantini D, Vanduffel W (2013) Emerging roles of the brains default network. Neuroscientist 19:76-87. CrossRef Medline

Mantini D, Gerits A, Nelissen K, Durand JB, Joly O, Simone L, Sawamura H, Wardak C, Orban GA, Buckner RL, Vanduffel W (2011) Default mode of brain function in monkeys. J Neurosci 31:12954-12962. CrossRef Medline

Mantini D, Corbetta M, Romani GL, Orban GA, Vanduffel W (2013) Evolutionarily novel functional networks in the human brain? J Neurosci 33:3259-3275. CrossRef Medline

Margulies DS, Vincent JL, Kelly C, Lohmann G, Uddin LQ, Biswal BB, Villringer A, Castellanos FX, Milham MP, Petrides M (2009) Precuneus shares intrinsic functional architecture in humans and monkeys. Proc Natl Acad Sci U S A 106:20069-20074. CrossRef Medline

Mars RB, Sallet J, Schüffelgen U, Jbabdi S, Toni I, Rushworth MF (2012a) Connectivity-based subdivisions of the human right temporoparietal junction area: evidence for different areas participating in different cortical networks. Cereb Cortex 22:1894-1903. CrossRef Medline

Mars RB, Neubert FX, Noonan MP, Sallet J, Toni I, Rushworth MF (2012b) On the relationship between the "default mode network" and the "social brain.” Front Hum Neurosci 6:189. CrossRef Medline

Mason MF, Norton MI, Van Horn JD, Wegner DM, Grafton ST, Macrae CN (2007) Wandering minds: the default network and stimulus-independent thought. Science 315:393-395. CrossRef Medline

McLaren DG, Kosmatka KJ, Oakes TR, Kroenke CD, Kohama SG, Matochik JA, Ingram DK, Johnson SC (2009) A population-average MRI-based atlas collection of the rhesus macaque. Neuroimage 45:52-59. CrossRef Medline

Mitchell JP, Macrae CN, Banaji MR (2006) Dissociable medial prefrontal contributions to judgments of similar and dissimilar others. Neuron 50: 655-663. CrossRef Medline

Moeller S, Nallasamy N, Tsao DY, Freiwald WA (2009) Functional connectivity of the macaque brain across stimulus and arousal states. J Neurosci 29:5897-5909. CrossRef Medline

Molenberghs P, Mesulam MM, Peeters R, Vandenberghe RR (2007) Remapping attentional priorities: differential contribution of superior parietal lobule and intraparietal sulcus. Cereb Cortex 17:2703-2712. CrossRef Medline

Nachev P, Kennard C, Husain M (2008) Functional role of the supplementary and pre-supplementary motor areas. Nat Rev Neurosci 9:856-869. CrossRef Medline

Nakahara K, Hayashi T, Konishi S, Miyashita Y (2002) Functional MRI of macaque monkeys performing a cognitive set-shifting task. Science 295: 1532-1536. CrossRef Medline

Nelissen K, Luppino G, Vanduffel W, Rizzolatti G, Orban GA (2005) Observing others: multiple action representation in the frontal lobe. Science 310:332-336. CrossRef Medline

Nelissen K, Borra E, Gerbella M, Rozzi S, Luppino G, Vanduffel W, Rizzolatti G, Orban GA (2011) Action observation circuits in the macaque monkey cortex. J Neurosci 31:3743-3756. CrossRef Medline

Ossandón T, Jerbi K, Vidal JR, Bayle DJ, Henaff MA, Jung J, Minotti L, Bertrand O, Kahane P, Lachaux JP (2011) Transient suppression of broadband gamma power in the default-mode network is correlated with task complexity and subject performance. J Neurosci 31:14521-14530. CrossRef Medline

Otten LJ, Rugg MD (2001) When more means less: neural activity related to unsuccessful memory encoding. Curr Biol 11:1528-1530. CrossRef Medline

Paxinos G, Huang XF, Petrides M, Toga A (2008) The Rhesus monkey brain in stereotaxic coordinates, Ed 2. London, England: Elsevier.
Perry RJ, Hodges JR (1999) Attention and executive deficits in Alzheimer's disease. Brain 122:383-404. CrossRef Medline

Pruessmann KP, Weiger M, Scheidegger MB, Boesiger P (1999) SENSE: sensitivity encoding for fast MRI. Magn Reson Med 42:952-962. CrossRef Medline

Quilodran R, Rothé M, Procyk E (2008) Behavioral shifts and action valuation in the anterior cingulate cortex. Neuron 57:314-325. CrossRef Medline

Raichle ME, MacLeod AM, Snyder AZ, Powers WJ, Gusnard DA, Shulman GL (2001) A default mode of brain function. Proc Natl Acad Sci U S A 98:676-682. CrossRef Medline

Rawley JB, Constantinidis C (2010) Effects of task and coordinate frame of attention in area 7a of the primate posterior parietal cortex. J Vis 10:12. CrossRef Medline

Reichenberg A, Harvey PD (2007) Neuropsychological impairments in schizophrenia: integration of performance-based and brain imaging findings. Psychol Bull 133:833-858. CrossRef Medline

Ridderinkhof KR, van den Wildenberg WP, Segalowitz SJ, Carter CS (2004) Neurocognitive mechanisms of cognitive control: the role of prefrontal cortex in action selection, response inhibition, performance monitoring, and reward-based learning. Brain Cogn 56:129-140. CrossRef Medline

Rilling JK, Barks SK, Parr LA, Preuss TM, Faber TL, Pagnoni G, Bremner JD, Votaw JR (2007) A comparison of resting-state brain activity in humans and chimpanzees. Proc Natl Acad Sci U S A 104:17146-17151. CrossRef Medline

Rossi AF, Bichot NP, Desimone R, Ungerleider LG (2007) Top-down attentional deficits in macaques with lesions of lateral prefrontal cortex. J Neurosci 27:11306-11314. CrossRef Medline

Rushworth MF, Behrens TE (2008) Choice, uncertainty and value in prefrontal and cingulate cortex. Nat Neurosci 11:389-397. CrossRef Medline

Sadaghiani S, Hesselmann G, Kleinschmidt A (2009) Distributed and antagonistic contributions of ongoing activity fluctuations to auditory stimulus detection. J Neurosci 29:13410-13417. CrossRef Medline

Salvador R, Suckling J, Coleman MR, Pickard JD, Menon D, Bullmore E (2005) Neurophysiological architecture of functional magnetic resonance images of human brain. Cereb Cortex 15:1332-1342. CrossRef Medline

Sauseng P, Klimesch W, Stadler W, Schabus M, Doppelmayr M, Hanslmayr S, Gruber WR, Birbaumer N (2005) A shift of visual spatial attention is selectively associated with human EEG alpha activity. Eur J Neurosci 22:2917-2926. CrossRef Medline

Shulman GL, Fiez JA, Corbetta M, Buckner RL, Miezin FM, Raichle ME, Petersen SE (1997) Common blood flow changes across visual tasks: II. Decreases in cerebral cortex. J Cogn Neurosci 9:648-663. CrossRef Medline

Shulman GL, McAvoy MP, Cowan MC, Astafiev SV, Tansy AP, d'Avossa G, Corbetta M (2003) Quantitative analysis of attention and detection signals during visual search. J Neurophysiol 90:3384-3397. CrossRef Medline

Shulman GL, Astafiev SV, McAvoy MP, d'Avossa G, Corbetta M (2007) Right TPJ deactivation during visual search: functional significance and support for a filter hypothesis. Cereb Cortex 17:2625-2633. CrossRef Medline

Shumway R, Stoffer D (2006) Time series analysis and its applications: with R examples (Springer texts in statistics). New York, NY: Springer.

Small DM, Gitelman DR, Gregory MD, Nobre AC, Parrish TB, Mesulam MM (2003) The posterior cingulate and medial prefrontal cortex mediate the anticipatory allocation of spatial attention. Neuroimage 18:633-641. CrossRef Medline

Smith SM, Fox PT, Miller KL, Glahn DC, Fox PM, Mackay CE, Filippini N, Watkins KE, Toro R, Laird AR, Beckmann CF (2009) Correspondence of the brain's functional architecture during activation and rest. Proc Natl Acad Sci U S A 106:13040-13045. CrossRef Medline

Spreng RN, Mar RA, Kim AS (2008) The common neural basis of autobiographical memory, prospection, navigation, theory of mind, and the default mode: a quantitative meta-analysis. J Cogn Neurosci 21:489-510. CrossRef Medline

Spreng RN, Stevens WD, Chamberlain JP, Gilmore AW, Schacter DL (2010) Default network activity, coupled with the frontoparietal control network, supports goal-directed cognition. Neuroimage 53:303-317. CrossRef Medline

Stafford JM, Jarrett BR, Miranda-Dominguez O, Mills BD, Cain N, Mihalas S, Lahvis GP, Lattal KM, Mitchell SH, David SV, Fryer JD, Nigg JT, Fair DA (2014) Large-scale topology and the default mode network in the mouse connectome. Proc Natl Acad Sci U S A 111:18745-18750. CrossRef Medline

Steinmetz MA, Constantinidis C (1995) Neurophysiological evidence for a role of posterior parietal cortex in redirecting visual attention. Cereb Cortex 5:448-456. CrossRef Medline 
Steinmetz MA, Connor CE, Constantinidis C, McLaughlin JR (1994) Covert attention suppresses neuronal responses in area $7 \mathrm{a}$ of the posterior parietal cortex. J Neurophysiol 72:1020-1023. CrossRef Medline

Teichert T, Grinband J, Hirsch J, Ferrera VP (2010) Effects of heartbeat and respiration on macaque fMRI: implications for functional connectivity. Neuropsychologia 48:1886-1894. CrossRef Medline

Uddin LQ, Kelly AM, Biswal BB, Castellanos FX, Milham MP (2009) Functional connectivity of default mode network components: correlation, anticorrelation, and causality. Hum Brain Mapp 30:625-637. CrossRef Medline

Utevsky AV, Smith DV, Huettel SA (2014) Precuneus is a functional core of the default-mode network. J Neurosci 34:932-940. CrossRef Medline

Van Essen DC (2004) Surface-based approaches to spatial localization and registration in primate cerebral cortex. Neuroimage 23 [Suppl. 1]:S97-S107.

Van Essen DC, Drury HA, Dickson J, Harwell J, Hanlon D, Anderson CH (2001) An integrated software suite for surface-based analyses of cerebral cortex. J Am Med Inform Assoc 8:443-459. CrossRef Medline
Vanduffel W, Fize D, Mandeville JB, Nelissen K, Van Hecke P, Rosen BR, Tootell RB, Orban GA (2001) Visual motion processing investigated using contrast agent-enhanced fMRI in awake behaving monkeys. Neuron 32:565-577. CrossRef Medline

Vincent JL, Patel GH, Fox MD, Snyder AZ, Baker JT, Van Essen DC, Zempel JM, Snyder LH, Corbetta M, Raichle ME (2007) Intrinsic functional architecture in the anaesthetized monkey brain. Nature 447:83-86. CrossRef Medline

Waltz JA, Kasanova Z, Ross TJ, Salmeron BJ, McMahon RP, Gold JM, Stein EA (2013) The roles of reward, default, and executive control networks in set-shifting impairments in schizophrenia. PLoS One 8:e57257. CrossRef Medline

Whitfield-Gabrieli S, Moran JM, Nieto-Castañón A, Triantafyllou C, Saxe R, Gabrieli JD (2011) Associations and dissociations between default and self-reference networks in the human brain. Neuroimage 55:225-232. CrossRef Medline

Zar J (1998) Biostatistical analysis, Ed 4. Upper Saddle River, NJ: Prentice-Hall. 